Planejamento da Mudança.

Um estudo de caso sobre a implementação do SAP na subsidiária brasileira da Ceras Johnson.

Flavia Pereira Nunes de Castro

\author{
RELATÓRIO FINAL \\ ESTÁGIO SUPERVISIONADO
}

CENTRO DE CIÊNCIAS SOCIAIS

\author{
CURSO DE GRADUAÇÃO \\ DEPARTAMENTO DE ADMINISTRAÇÃO
}

Rio de Janeiro, Maio, 2005.

IAG - INSTITUTO DE ADMINISTRAÇÃO E GERÊNCIA

ESCOLA DE NEGÓCIOS DA PUC-Rio

http://www.puc-rio.br/iag 
Flavia Pereira Nunes de Castro

Planejamento da Mudança.

Um estudo de caso sobre a implementação do SAP na subsidiária brasileira da Ceras Johnson.

\author{
RELATÓRIO FINAL \\ ESTÁGIO SUPERVISIONADO
}

Orientador: Ricardo Nolla

Área: Organização

DEPARTAMENTO DE ADMINISTRAÇÃO

Maio, 2005. 


\title{
Planejamento da Mudança. \\ Um estudo de caso sobre a implementação do SAP na subsidiária brasileira da Ceras Johnson.
}

\author{
Planning the Change. \\ A case about the SAP Implementation on SCJ Brazil
}

\author{
Flavia Pereira Nunes de Castro
}

Ricardo Nolla

RESUMO

Tendo em vista a acelaração das mudanças ocorridas no ambiente organizacional e a crescente busca por novas tecnologias e soluções, a empresa S.C. Johnson assim como muitas outras multinacionais vem ao longo do tempo optando por mudar seus processos de negócio afim de obter benefícios provindos dos avanços da Tecnologia da Informação. Mais especificamente, o trabalho se propõe a avaliar a forma pela qual a mudança será gerenciada no momento em que a empresa se encontra em fase de implementação de um modelo de ERP, o SAP $\mathrm{R} / 3$.

\begin{abstract}
With the acceleration of organization changes and the crescent search for new tecnologies and solutions, the S.C. Johnson as well as other multinationals are looking forward to change their process on behavior to take advance using the benefits from the Tecnology of Information. More specifically, this application is going to evaluate the change management process that this company is going through at the moment of SAP R/3 implementation.
\end{abstract}

PALAVRAS-CHAVE

Mudança, Planejamento, SAP

KEYWORDS

Change, Planning, SAP

ÁREA:

Organização 


\section{SUMÁRIO}

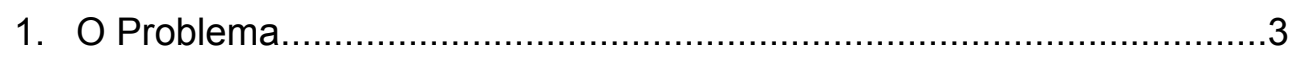

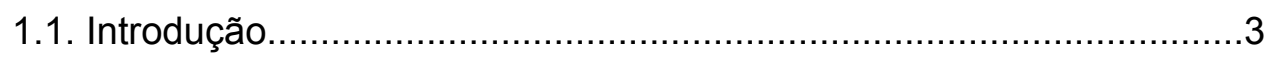

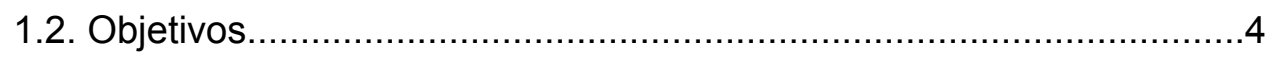

1.3. Delimitação do estudo............................................................... 4

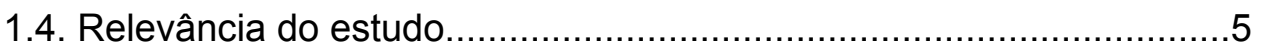

2. Referencial Teórico...................................................................... 6

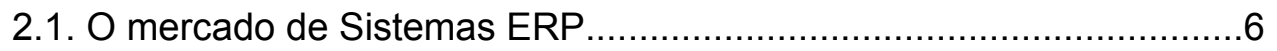

2.2. Decisão de adoção de um software ERP...................................... 7

2.3. Estratégias de implementação..................................................10

2.4. Administração de projetos........................................................12

2.5. Fatores críticos de sucesso......................................................13

2.6. Mudanças organizacionais....................................................17

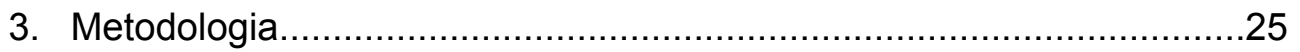

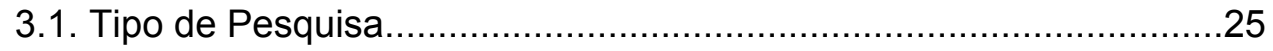

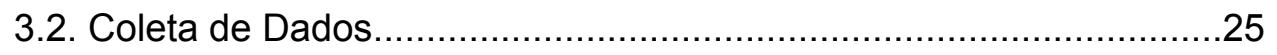

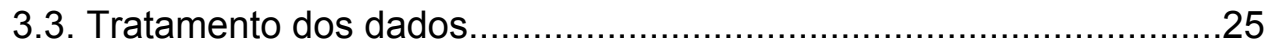

3.4. Limitações do método................................................................26

4. Análise Crítica.......................................................................27

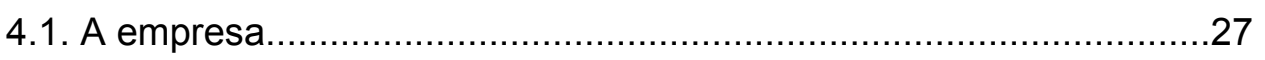

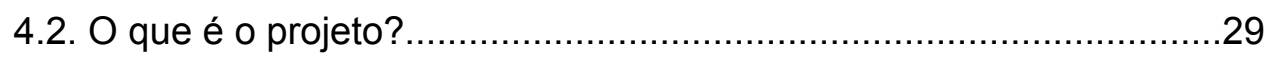

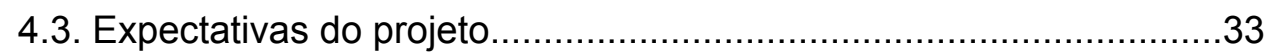

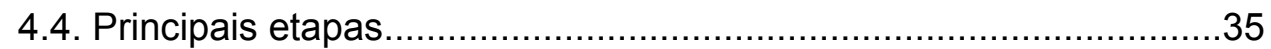

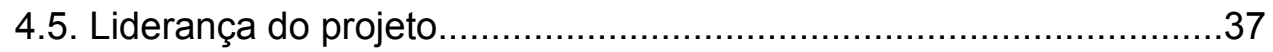

4.6. Transferência de conhecimento.................................................38

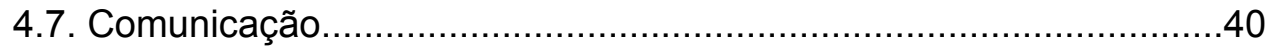

4.7.1 Veículos de Comunicação.......................................................42

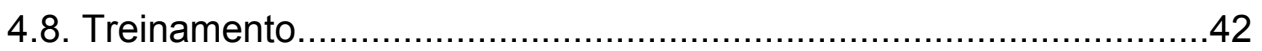

4.9. Mudança - Plano de OCM..................................................44

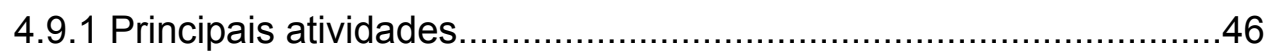

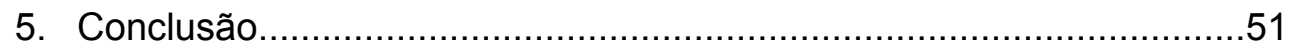

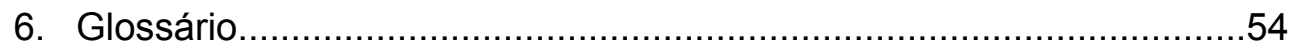

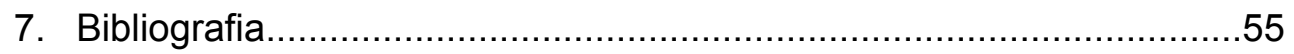




\section{ÍNDICE DE FIGURAS}

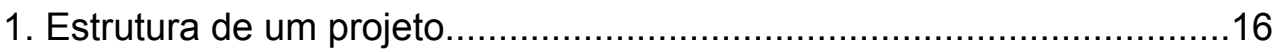

2. Categorias de produtos comercializados pela SCJ Brasil.....................28

3. Plano de implementação do Global One...............................................30

4. Tipos de softwares utilizados regionalmente......................................31

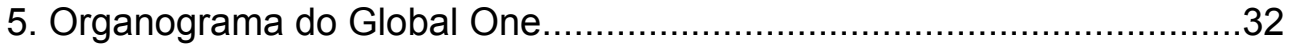

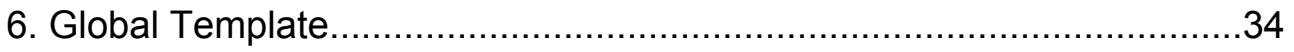

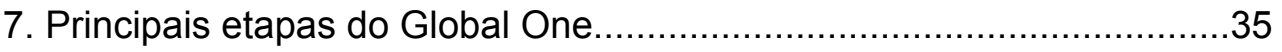

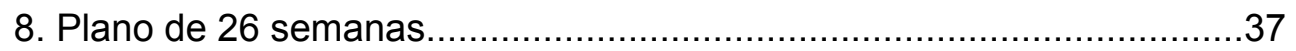

9. Cronologia de transferência de conhecimento.....................................39

10. Cronologia de transferência de conhecimento detalhada....................39

11. Comunicação virtual....................................................................... 41

12. Conduzindo as pessoas através da mudança..................................42

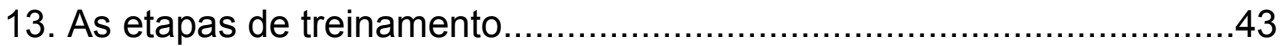

14. Preparação do material de treinamento.............................................44

15. Pesquisa de principais atividades relacionadas ao projeto...................45

16. Altos e baixos esperados durante as etapas do projeto.......................45

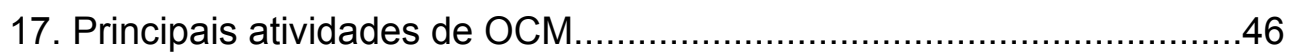

18. Pesquisa de avaliação de risco da mudança.....................................47

\section{ÍNDICE DE QUADROS}

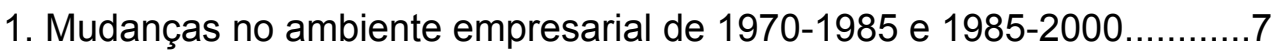

2. Origem, composição e atribuições dos participantes de um projeto......16

3. Vantagens, inconvenientes e riscos de mudanças planejadas..............20

4. Razões pelas quais as pessoas resistem à mudança...........................21 


\section{O Problema}

\subsection{Introdução}

Nos últimos anos, o mercado brasileiro, assim como, o mercado mundial, vem presenciando uma crescente demanda por softwares destinados à gestão empresarial, os sistemas ERP - Enterprise Resourse Planning (Planejamento de Recursos Empresariais).

Esses sistemas não são novidades, mas somente nos últimos anos, os grandes pacotes de software, que fornecem uma solução única para gestão de toda a organização, começaram a ser presença marcante em empresas no mundo todo.

A crescente busca por essas soluções é devida à incapacidade dos sistemas atuais em atender todas as necessidades da empresa, a falta de atualização dos sistemas e a não integração apropriada de dados e informações - muitas vezes vindas de uma grande variedade de sistemas.

Ao mesmo tempo, as empresas vêm passando por várias pressões para redução de custo, aumento de consumo, concorrência acirrada, abertura de mercados a novos competidores, mudanças tecnológicas realizadas pelos concorrentes e outros fatores que tem levado a buscar soluções de tecnologia cada vez melhores.

Estes e outros motivos resultaram na busca pela implementação de sistemas ERP, principalmente dos softwares dos grandes competidores desse mercado.

Porém os projetos de implementação de um sistema ERP normalmente são considerados como demorados e caros. Em função disso, fracassos na implementação desses projetos normalmente podem se tornar grandes desastres para todos os envolvidos.

A TI - Tecnologia da Informação não tem poder, por si só, de provocar mudanças na organização ou obrigar os usuários a fazê-lo, sem que estejam dispostos a tal. Um projeto ERP não deve ser simplesmente uma implementação de sistemas, mas também um projeto de mudança de processos, pois, caso contrário, os benefícios podem não ser obtidos.

A forma pela qual, a mudança é gerenciada pode fazer a diferença entre sobreviver ou não. Existem vários obstáculos que dificultam o processo de mudança organizacional, principalmente pessoas que, em todos os níveis da organização são muito resistentes, muito reativas e extremamente ligadas aos 
seus velhos hábitos de gerenciamento. É necessária a flexibilidade ás constantes adaptações exigidas por um ambiente atingido permanentemente por mudanças.

Além disso, as consultorias especializadas na implementação de sistemas ERP possuem material próprio acompanhado de uma metodologia e destinado somente a auxiliar no projeto de implementação, funcionando mais como "receitas prontas", o que pode ser crítico para o sucesso do projeto, se a cultura organizacional não for levada em consideração.

O desenvolvimento desse trabalho foi motivado pela grande atenção que, a implementação desse projeto tem provocado, devido à importância a ele atribuída e pelo tamanho do empreendimento na subsidiária brasileira da S.C. Johnson \& Son. Inc.

Assim sendo, este trabalho se propõe a responder a seguinte questão:

Como a SCJ irá gerenciar a mudança necessária para instalação de um novo modelo de gestão?

\subsection{Objetivos}

Objetivo final:

Avaliar a importância e os cuidados a serem tomados quanto ao planejamento da mudança para o sucesso da implementação de projetos de um novo sistema de gestão, mais particularmente do pacote SAP para gestão empresarial.

Objetivos intermediários:

Identificar as principais motivações que levaram a empresa a iniciar uma estratégia de implementação de SAP.

Verificar a presença de determinados fatores no projeto, que são considerados como críticos para o sucesso do mesmo.

Apresentar a empresa e descrever seu momento de mudança.

Mostrar as etapas a serem cumpridas para possibilitar a mudança desejada.

\subsection{Delimitação do Estudo}

O presente estudo se propõe a analisar a forma como foi gerenciado o planejamento da mudança em prol da adaptação da empresa ao processo de implementação do SAP. Não tem, portanto, a intenção de abordar todas as possíveis medidas adotadas para a implementação de um sistema ERP 
destinado à gestão empresarial visto que é um tema muito abrangente e não caberia nesse trabalho prolongarmos excessivamente a questão.

Não faz parte do escopo desse trabalho a análise das mudanças ocorridas na empresa no período que sucede e precede o período referido ao planejamento da mudança, apenas citá-las na medida que ajudem a explicar o processo de planejamento em si.

Apesar de implementações já terem ocorrido em dezessete subsidiárias da S.C. Johnson \& Son. Inc. ao redor do mundo, serão estudados apenas os efeitos que provocaram na implementação na empresa no Brasil e os aprendizados que podem ser tirados desses modelos anteriores.

Segundo o critério de delimitação mencionado, a pesquisa desenvolveu-se em torno de um estudo de caso de uma subsidiária brasileira de uma organização familiar americana, a Ceras Johnson, que atua no ramo de produtos domésticos e tem como característica predominante a utilização de estratégias globais em cada uma de suas subsidiárias.

\subsection{Relevância do Estudo}

O fato desse assunto ter assumido uma importância relativamente grande na área de Tecnologia da Informação, principalmente devido aos grandes investimentos realizados e por esperar-se que, além dos valores já investidos por muitas empresas nesse tipo de projeto, muitas outras iniciem grandes investimentos, parece justificar a realização de estudos que possam auxiliar fornecedores, consultores e empresas usuárias a identificar fatores que sejam importantes para facilitar o desenvolvimento do projeto e aumentar as chances de sucesso.

O trabalho se propõe também a oferecer sugestões a administradores para que utilizem algumas dessas medidas em suas empresas que estejam passando pelo mesmo processo. Dessa forma, este estudo pode ser uma contribuição no sentido de melhorar o processo de implementação de projetos ERP e aumentarIhes, as chances de sucesso.

O estudo também é importante para que as empresas e seus funcionários tomem consciência de que as mudanças existem e que aquelas que não se adaptarem, não evoluírem, serão naturalmente excluídas em um futuro próximo.

Além disso, os resultados serão de extremo interesse da empresa em questão, na medida que poderão ser adotadas algumas das medidas e propostas. 


\section{Referencial Teórico}

\subsection{O Mercado de Sistemas ERP}

Apesar da Internet ter sido um dos assuntos principais da mídia especializada nos últimos anos, os pacotes de gestão empresarial estão ganhando cada vez mais espaço. Muito provavelmente, algumas das principais razões para isso são a presença desse tipo de software nas principais empresas ao redor do mundo e nos valores envolvidos nesse mercado.

A maior expansão do mercado ERP, ocorre na América Latina e na Ásia, regiões com uma rápida expansão econômica e que enfrentam pressões para se igualar aos EUA e Europa.

Os fornecedores de software ERP são principalmente empresas européias e americanas.

Existe no mercado americano de ações, uma acentuada confiança nas empresas que lideram esse segmento, o que se reflete no valor das suas ações.

No Brasil, as maiores empresas fornecedoras de sistemas ERP são a SAP e a Oracle.

Existem diversas definições do que é um sistema ERP - ou sistema de gestão empresarial. A definição dada pela APICS para ERP é a seguinte:

ERP ( Enterprise Resource Planning ) é uma extensão do conceito de planejamento de recursos de manufatura padronizados pela APICS ( American Production and Inventory Control Society). Estes sistemas são os principais sistemas de transações utilizadas nas modernas plantas de manufatura para automatizar e integrar os processos de administração de negócios e da produção. Registrando transações, o recebimento de estoque ou o processamento de uma ordem de produção - o sistema rastreia os recursos usados na administração financeira, de manufatura e de distribuição.

Muitas das necessidades organizacionais sofreram grandes alterações, o que passou a demandar sistemas com diferentes características das existentes até então. $\mathrm{O}$ quadro abaixo mostra algumas mudanças no ambiente empresarial nesses dois períodos distintos: 
Quadro 1

\begin{tabular}{|l|l|}
\hline De ( período de $\mathbf{1 9 7 0}$ - 1985 ) & Para ( período de 1985 - 2000 ) \\
\hline Ciclo de produção com lead time longo & Lead time curto e orientado ao mercado \\
\hline Produção em massa & Pequenos lotes com muita variação \\
\hline Domínio das grandes corporações & Domínio das corporações ágeis \\
\hline Integração vertical & Negócios virtuais, com parcerias \\
\hline Produção interna & Extensiva terceirização, contrato de trabalho \\
\hline Fontes de capital fáceis & Fontes de capital difíceis \\
\hline Margens largas & Grande pressão sobre margens \\
\hline Mudanças técnicas e de mercado lentas & Mudanças técnicas e de mercado rápidas \\
\hline Centrado na produção & Centrado no cliente \\
\hline Produção doméstica & Produção com parcerias globais \\
\hline Alto custo com média gerência & Pressão para organizaçães "enxutas" \\
\hline Foco no controle de estoque & Resposta ao cliente, foco no custo \\
\hline Baixa confiança em computadores & Alta confiança em computadores \\
\hline Poder computacional limitado e caro & Poder computacional abundante e barato \\
\hline
\end{tabular}

Outras características de um sistema ERP dizem respeito à operação globalizada e diversidade de métricas. Um sistema ERP permite a operação em diversas plantas, que podem estar distribuídas ao redor do mundo, possibilitando um fornecimento global para peças e serviços e distribuição internacional. Isso pode exigir diferentes métricas para mensuração de desempenho em diferentes paises, porém sempre operando de maneira integrada.

Um fato importante é que os sistemas ERP se utilizam, entre outras coisas, dessas tecnologias para produzir um banco de dados único e integrado, o que permite que diversas decisões sejam tomadas enxergando a empresa como um todo, em vez de olhar as unidades separadamente e tentar coordenar a informação manualmente.

\subsection{Decisão de Adoção de um Software ERP}

Provavelmente, somente as características de um sistema ERP não seriam suficientes para provocar e manter aquecida a demanda que vem ocorrendo por este tipo de sistema. Alguns pontos são apontados como motivadores da escolha de um sistema integrado.

A idéia de um sistema único, com uma interface única, atualizado com as últimas novidades tecnológicas e de negócios, com todos os dados da empresa centralizados e permitindo tomada de decisão rápida, sem dúvida é um grande atrativo para a escolha de um sistema ERP e, segundo a empresa de consultoria Deloitte \& Touche, das empresas americanas que substituíram sistemas, $70 \%$ optaram por pacotes, em detrimento dos sistemas próprios. 
Fatores como a busca por aumento no desempenho dos negócios, redução de estoques, redução de prazos para atendimento de pedidos, aumento na agilidade da empresa e outros influenciam no processo de adoção de um ERP.

A questão de instalar pacotes de software como um recurso de melhoria de competitividade, ao invés de desenvolvê-los internamente, não é nova, simplesmente está sendo reutilizada em relação aos sistemas ERP. A citação a seguir, da APICS, datada em 1979, demonstra essa preocupação há quase 20 anos, bem antes do surgimento do conceito ERP.

"Os negócios hoje estão se tornando mais e mais competitivos. Com o uso do capital, terra, construções e estoque, para não citar as taxas de retorno que estão atingindo níveis recordes, vocês deve "sistematizar" para continuar nos negócios... Amanhã pode ser muito tarde. Seus competidores já começaram. [ ...] pacotes podem ser instalados em uma fração do tempo tomado para se desenvolver um sistema internamente. A instalação pode ser em qualquer lugar, de imediato, em até um quarto do tempo de desenvolvê-lo internamente."

A discussão entre abordagens de desenvolvimento de sistemas de informação "caseiros", criados por uma equipe interna e direcionados especificamente a um conjunto de necessidades da empresa, ou a aquisição de pacotes de software, prontos para serem instalados e genéricos o suficiente para atender a todas as necessidades da empresa possui defensores em ambos os lados. Breslin (1986) cita alguns dos principais argumentos na relação entre o desenvolvimento de software e a aquisição de pacotes.

Argumentos favoráveis à aquisição de pacotes:

- Pacotes, geralmente, são tecnologicamente superiores a produtos "caseiros" (isto ocorre porque as empresas de software investem pesado no desenho original e despejam recursos de P\&D Pesquisa e Desenvolvimento - em melhorias do produto);

- Existe, teoricamente, menos risco em implementar pacotes que já são produtos "testados" e funcionando em diversos locais;

- Eles podem, de forma conceitual, ser implementados em menor tempo que o esforço de desenvolvimento inicial de um sistema;

- Eles, logicamente, requerem menos pessoal de informática, um recurso caro e escasso. 
Argumentos contrários à aquisição de pacotes:

- Pacotes, por definição, são genéricos e não refletem as condições de operações contrastantes que são encontradas nas empresas de diferentes ou, às vezes, do mesmo tipo de indústria. Isto é um contraste para os desenvolvimentos customizados, sistemas desenvolvidos internamente nas empresas por funcionários que conhecem, pelo menos, até certo ponto, a natureza dos negócios e desenhados para um conjunto específico e requerimentos;

- Quando sistemas são desenvolvidos internamente, existe alguém, algumas vezes muitas pessoas (usualmente analistas de sistemas e programadores) dentro da empresa, que compreendem o software. Esta é mais uma exceção que uma regra em relação aos pacotes;

- As apresentações de vendas e (pré-vendas) marketing das companhias de software usualmente não fornecem informação detalhada para um julgamento verdadeiro da aplicabilidade do pacote para uma determinada operação. É necessário considerável experiência prática (ou ferramentas adequadas) com um sistema para compreender totalmente suas capacidades e limitações;

- As ferramentas oferecidas para planejar e monitorar uma instalação são limitadas e existe tremenda variação na qualidade de sistemas e suporte fornecidos para os usuários finais. Alguns fornecedores possuem programas de treinamento nas quais faltam o que realmente é necessário para operar o sistema efetivamente;

- A conversão de dados dos sistemas antigos ou dos artigos manuais raramente recebem o planejamento e a atenção que merecem. Tipicamente, os fornecedores oferecem pouca ou nenhuma orientação nesta tarefa essencial;

- Alguns fornecedores de softwares persistem em uma busca contínua para fornecer cada vez mais novas características e funções em seus produtos. Isto pode afastá-los de seus objetivos originais e resultar em sistemas muito complexos para serem compreendidos, usados adequadamente ou instalados. 


\subsection{Estratégias de Implementação}

Muitos dos problemas e riscos aos quais os projetos de ERP estão sujeitos dependem em grande parte das estratégias adotadas em relação aos mesmos. O gerenciamento de um processo ERP pode assumir diversas formas, dependendo das diretrizes de sua gestão, suas missões e dos responsáveis pelo mesmo.

Existem algumas opções distintas para o momento da implantação (ou conversão) de um sistema ERP - o instante em que o sistema já está em condições de passar a operar e sustentar a operação da empresa. A discussão da mesma é particularmente significativa em ambientes onde já existem sistemas, que serão substituídos, total ou parcialmente, pelo pacote ERP. A seguir alguns dos métodos existentes:

- Conversão direta, conversão única ou big bang;

- Conversão em fases, conversão parcial;

- Conversão em paralelo;

- Conversão em paralelo com piloto;

- Conversão em paralelo limitado;

- Conversão em paralelo retroativo;

A conversão direta, ou big bang é reconhecida como o método mais arriscado e mais rápido. Consiste, em grosso modo, em desativar os sistemas antigos em um momento, converter os dados necessários para o novo sistema e passar a utilizá-lo abandonando definitivamente os sistemas antigos.

Os riscos inerentes a esse processo são vários, mas os principais residem no fato de que o sistema foi configurado, suas centenas de tabelas interdependentes parametrizadas e testadas, mas é praticamente impossível que todas as situações que ocorrem no dia-a-dia tenham sido previstas, sendo inevitável que erros ou problemas venham a ocorrer. Também é comum que surjam erros em módulos que funcionavam corretamente sozinhos, mas passam a apresentar problemas quando todo o sistema está interligado (Piszczalski 1997).

Também é extremamente difícil que os usuários consigam - apesar da quantidade de treinamento recebida - abandonar um sistema em um instante e obter desempenho satisfatório no novo sistema no instante seguinte. Levando em conta que a empresa dependa do sistema para a sua sobrevivência, os riscos existentes são consideráveis (Lozinsky - 1996). 
Seus principais benefícios residem em não haver necessidade de se produzir interfaces de software e, muitas vezes, ser a única opção possível. Radosevich (1997) cita o caso da Quantum, um fabricante de discos para computadores com faturamento de US\$ 4,4 bilhões que adquiriu um outro grande fabricante. Os sistemas de ambos eram ultrapassados e incompatíveis entre si, e a empresa tinha uma grande urgência que suas duas operações ao redor do mundo passassem a funcionar como uma só, o que certamente minimizou os riscos e custos da companhia parada por uma semana sem poder fazer qualquer negócio, como resultado de uma implantação de tipo big bang.

A alternativa da conversão em fases, ou parcial, resume-se na colocação do sistema por módulos (ou partes), um por vez. Isso normalmente implica o desenvolvimento de uma grande quantidade de software para atuar como interface entre os sistemas atuais e o módulo que está sendo implantado. Essas interfaces importam e exportam dados entre os sistemas, permitindo que a empresa trabalhe com os sistemas antigos e os novos módulos ao mesmo tempo. À medida que novos módulos vão "ao ar", as interfaces são descartadas, até que todo o pacote esteja em funcionamento e as mesmas não sejam mais necessárias. Esse método é considerado seguro, porém as interfaces entre pacotes ERP e outros sistemas são condenadas por muitos autores, seja por exigirem custos de desenvolvimento e serem posteriormente descartadas, ou seja por serem uma fonte de erros (Radosevich - 1997).

As conversões em paralelo seguem todas uma idéia geral, que consistem no funcionamento dos sistemas antigos ao mesmo tempo que o pacote ERP, com a constante comparação dos resultados obtidos, até que os mesmos sejam iguais e não haja mais problemas com o novo pacote. Nesse momento, os sistemas antigos podem ser desligados, passando o pacote ERP a ser o sistema oficial da empresa.

Esse método é bastante seguro, pois a empresa somente passa para o novo sistema com a segurança do seu funcionamento, mais exige um esforço muito grande, pois todas as operações devem ser feitas nos dois sistemas, para que os dados possam ser conferidos. Isto implica, no mínimo, no dobro de trabalho por parte dos usuários, havendo ainda, muitas vezes, questões tecnológicas envolvidas, tais como usar um terminal de um determinado equipamento para o sistema antigo e um microcomputador para o novo sistema (Lozinsky - 1996).

Os métodos, em paralelo, com piloto, limitado e retroativo são citados por Lozinsky (1996) como variações do método anterior. A conversão em paralelo 
com piloto consiste no método paralelo feito somente em uma unidade de negócios - em uma parte pequena da empresa. Quando o piloto funcionar, ele deve ser replicado para as demais unidades. O método paralelo limitado, por sua vez, não exige que todas as operações sejam feitas nos dois sistemas, podendo ser feitas no novo sistema, por exemplo, por amostragem. O que importa é que a amostra reflita todos os casos possíveis e que ocorrem no sistema antigo. No método paralelo retroativo, pode haver um lapso, por exemplo, em alguns dias, entre as operações nos dois sistemas. O que importa é que os resultados sejam os mesmos.

Seja qual for a estratégia de conversão escolhida, ela deve ser o resultado de uma análise cuidadosa dos diversos fatores envolvidos. Devem ser consideradas as necessidades e objetivos da empresa em relação ao projeto, os seus recursos disponíveis - tempo, dinheiro, pessoal, consultoria - para a execução, além de outros fatores como o envolvimento e participação dos usuários e da equipe de projeto.

\subsection{Administração de Projetos}

Todo projeto possui um início e término definidos - não importando se será longo ou curto - seja quando o seu objetivo é atingido ou quando o mesmo é encerrado pela constatação de que seu objetivo não será atingido.

Mesmo que outros já tenham sido elaborados, um projeto sempre é único, pois o mesmo software pode ser implementado várias vezes, mas sempre serão diferentes empresas, necessidades e envolvidos.

$\mathrm{Na}$ administração de projetos podem ser estudadas as abordagens de ciclo de vida de projeto, planejamento de projetos, acompanhamento e controle de projetos, alternativas organizacionais para projetos, papéis e responsabilidades do gerente de projetos, desenvolvimento de equipe de projetos, implantação e avaliação de projetos.

De acordo com Kruglianskas (1993), todo projeto apresenta um ciclo de vida que pode ser decomposto em seis fases: pré-concepção, quando se procura identificar e analisar o problema e procurar alternativas de solução, concepção, onde se estabelecem as etapas, prazos e custos, estruturação, decomposição das etapas em atividades, execução das etapas, transferência dos resultados e avaliação dos resultados obtidos.

Uma boa administração integra essas atividades de forma coerente para guiar uma proposta de desenvolvimento de um novo produto ou processo de sua fase conceitual até seu encerramento bem sucedido. 
Cada fase deve possuir uma descrição detalhada de seu início, objetivos, término, definição de quais atividades devem ser desenvolvidas e quem deve estar envolvido.

O gerenciamento de projetos é considerado uma atividade crítica e diretamente responsável pelo sucesso ou fracasso do projeto. O gerenciamento de projetos de Sistemas de Informação é apontado, segundo dados do Gartner Group, como "pior do que horrível", pois produz perdas que ultrapassam US\$ 100 bilhões anualmente. Falta de planejamento de gerenciamento do projeto são as principais razões para estouro de $1 / 3$ dos orçamentos de projetos de software, com perdas anuais de US\$ 80 bilhões.

O acompanhamento e controle de cada fase e atividade do projeto exige um gerente de projeto com diversas habilidades:

- Liderança: estabelecer direcionamentos, alinhar as pessoas, motivar e inspirar os membros da equipe;

- Comunicação: promover a troca de informações claras, interna e externamente ao projeto;

- Negociação: negociar durante toda a duração do projeto, principalmente em relação a mudanças de escopo, custo, duração, contratos, recursos e fornecedores;

- Solução de problemas: identificar sintomas e causas, analisar as alternativas viáveis e promover tomada de decisão para solucionálo;

- Influenciar a organização: compreender a estrutura da organização e dos envolvidos, com o objetivo de "fazer as coisas acontecerem".

\subsection{Fatores Críticos de Sucesso}

A presença de um certo grupo de fatores, considerados críticos, possui grande influência no projeto e aumenta as chances de sucesso deste.

Slevin \& Pinto (1986) apresentam um conjunto de 10 fatores, considerados pelos mesmos como críticos para o sucesso no gerenciamento e implementação de projetos:

- Missão do projeto;

- Apoio da alta administração;

- Plano de cronograma do projeto;

- Consulta aos clientes;

- Pessoal; 
- Atividades técnicas;

- Aceitação do cliente;

- Monitoração e feedback;

- Comunicação;

- Crises e desvios.

Já os fatores apresentados por Grover (1995) são os seguintes:

- Gerenciamento da mudança;

- Competência tecnológica;

- Planejamento estratégico;

- Estrutura de tempo;

- Apoio da administração;

- Recursos humanos;

- Delineamento do processo;

- Gerenciamento do projeto;

- Planejamento tático.

Diversos outros autores também já propuseram fatores considerados pelos mesmos como críticos. Larsen \& Myers (1997) citam os fatores apresentados por Hammer \& Champy e Robb (1993):

- Apoio da alta administração;

- Um líder de projeto respeitado e comprometido;

- Uma equipe de projeto formada por um composto de funcionários e consultores;

- Os melhores funcionários da empresa em cada área funcional;

- Uma estratégia de comunicação e gerenciamento de mudanças, bem planejamos;

- Uma metodologia efetiva.

Porém um projeto não é estático e possui diferentes necessidades em diferentes níveis, durante seu desenrolar. Portanto, a existência de um conjunto de fatores, por si só, não garantem o sucesso ou fracasso de um projeto.

Em projetos ERP os principais pré-requisitos são o apoio e comprometimento da alta administração, objetivos claros e definidos, usuários capacitados e disponíveis, existência dos recursos necessários, mudança nos processos de negócios, presença de uma consultoria externa e outros. 
Bancroft (1998) cita nove fatores que considera como críticos para implementação de sistemas ERP:

- Compreender a cultura da empresa;

- Iniciar a mudança dos processos de negócios antes da implementação;

- Manter uma comunicação constante, mas não em termos técnicos;

- Garantir um forte apoio dos executivos para o projeto;

- Possuir um gerente de projetos que possa negociar em todos os níveis;

- Escolher uma equipe de projeto balanceada (entre a área de sistemas e a área de negócios);

- Escolher uma boa metodologia de projeto;

- Treinar os usuários e garantir apoio para mudanças de cargo;

- Esperar que problemas surjam.

Outro fator que pode ser considerado importante para o sucesso de um projeto ERP é o correto alinhamento entre os objetivos da organização e o que será atingido após a implantação do sistema.

Em relação ao alinhamento de objetivos é importante o projeto ser visto como de toda a organização, como um objetivo comum e não como de interesse exclusivo de uma área específica. Isso porque a implementação e o uso do novo sistema vão exigir sacrifícios maiores de alguma área em específico, para obtenção dos benefícios desejados.

Gerenciar as expectativas em relação aos objetivos é uma medida de cautela no projeto, pois, muitas vezes, o ERP não faz algumas coisas tão bem como elas podem ser feitas hoje, mas o principal motivo da implantação é a integração e a visibilidade, além dos outros possíveis benefícios, o que exige uma negociação quanto as suas funcionalidades.

Outro dos requisitos para garantir o sucesso é a necessidade de uma alto executivo que deve estar convencido dos benefícios e da importância do projeto, principalmente no caso de resistências de outras áreas da organização

Além disso, é importante que toda a alta administração esteja envolvida no processo durante e depois da implantação. A escolha dos membros da empresa que participarão da equipe também é vital para o seu sucesso.

A equipe que participa do projeto ERP pode assumir diversas configurações, dependendo do seu porte e características, distribuição 
geográfica, módulos a serem implementados, participação da consultoria e do fornecedor, além de outros fatores particulares de cada projeto.

Lozinsky (1996) apresenta uma estrutura de projeto.

Figura 1

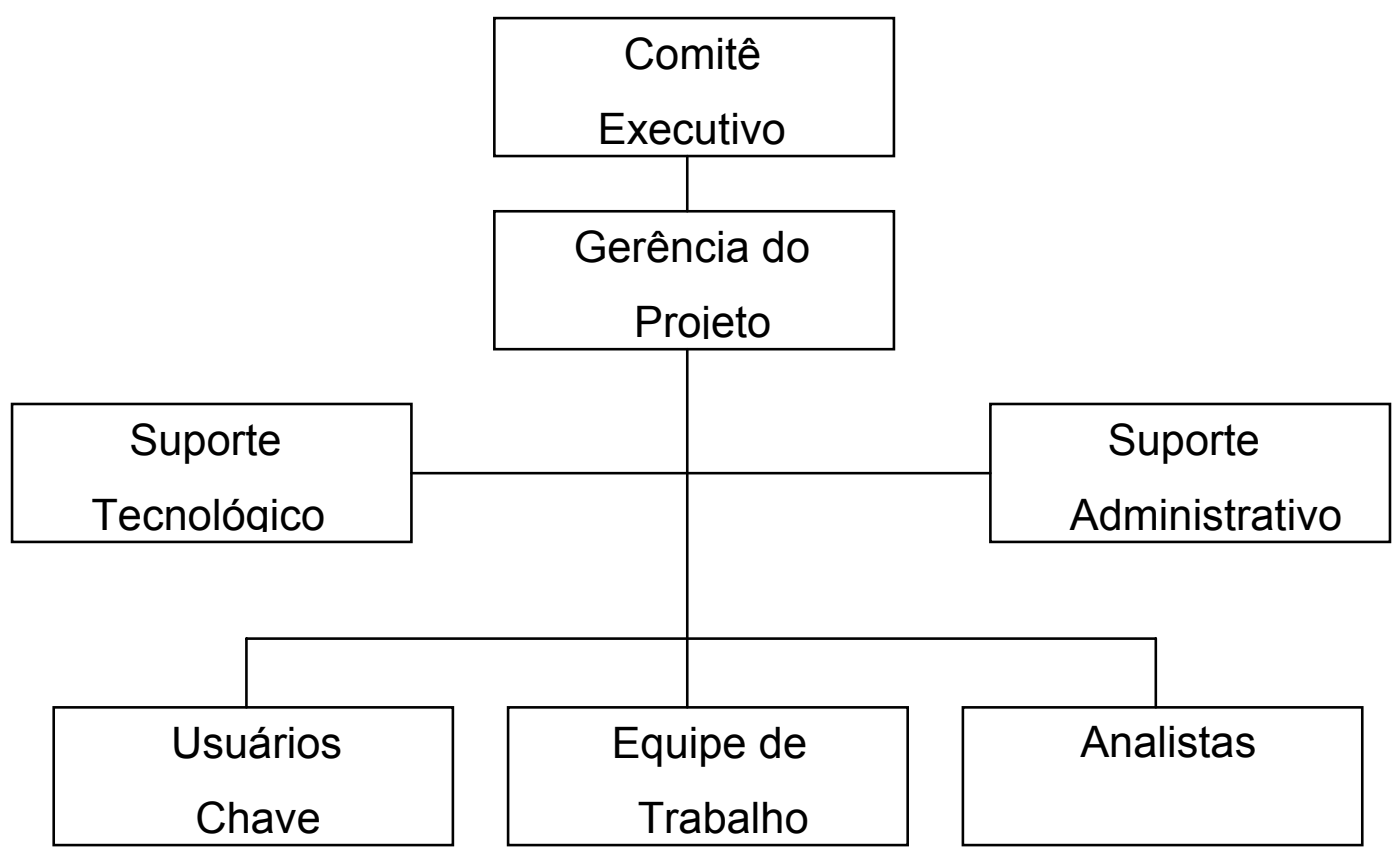

Com base nesse modelo o quadro abaixo mostra os diversos participantes desse modelo, sua origem e atribuições.

Quadro 2

\begin{tabular}{|c|c|c|}
\hline Participante & Origem / Composição & Atribuições \\
\hline Comitê Executivo & $\begin{array}{c}\text { Formado por representantes da Alta } \\
\text { Administração da empresa (Diretores, o } \\
\text { próprio Presidente da empresa, e outras } \\
\text { pessoas com poder de decisão), o } \\
\text { responsável geral pelos trabalhos da } \\
\text { consultoria contratada e, eventualmente, } \\
\text { alguém do nível executivo do fornecedor do } \\
\text { pacote de software adquirido. }\end{array}$ & $\begin{array}{c}\text { Avalia andamento do projeto. } \\
\text { Aprova resultados intermediários e } \\
\text { finais. Provê recursos necessários. } \\
\text { Toma decisões em questões que } \\
\text { afetam o escopo definido. Negocia } \\
\text { honorários ou custos de serviços } \\
\text { dos consultores ou do fornecedor } \\
\text { do pacote. }\end{array}$ \\
\hline $\begin{array}{c}\text { Gerência do } \\
\text { Projeto }\end{array}$ & $\begin{array}{c}\text { Formada pelo profissional da consultoria que } \\
\text { lidera os trabalhos "em campo" e pelo } \\
\text { representante da empresa - coordenador } \\
\text { interno. }\end{array}$ & $\begin{array}{c}\text { Responsável pela condução dos } \\
\text { trabalhos programados. Administra } \\
\text { os recursos de: pessoal, } \\
\text { cronograma, custos, despesas. } \\
\text { Responsável pela comunicação } \\
\text { entre as áreas do projeto. Presta } \\
\text { contas ao comitê executivo. }\end{array}$ \\
\hline
\end{tabular}




\begin{tabular}{|c|c|c|}
\hline Equipe de Trabalho & $\begin{array}{l}\text { Formada pelos consultores contratados, com } \\
\text { experiência no pacote em implementação. } \\
\text { Normalmente, existem profissionais diferentes } \\
\text { para cada funcionalidade do pacote. }\end{array}$ & $\begin{array}{l}\text { Levanta informações com os } \\
\text { usuários. Modela e configura o } \\
\text { pacote de acordo com as } \\
\text { necessidades da empresa. } \\
\text { Acompanha o projeto até o final. }\end{array}$ \\
\hline Usuários Chave & $\begin{array}{l}\text { Formado por um grupo de usuários de } \\
\text { diversas áreas. Indivíduo com autonomia, } \\
\text { liderança, conhecimento técnico, respeito dos } \\
\text { demais usuários e formador de opinião. }\end{array}$ & $\begin{array}{c}\text { Define como o sistema vai } \\
\text { funcionar em todos os detalhes. } \\
\text { Discute e participa da modelagem } \\
\text { de processos. Testa o software. } \\
\text { Treina os demais usuários de sua } \\
\text { área. }\end{array}$ \\
\hline Analistas & $\begin{array}{l}\text { Profissionais da área de Informática com } \\
\text { conhecimento de sistemas atuais e dos } \\
\text { processos de negócio da empresa. }\end{array}$ & $\begin{array}{l}\text { Desenvolve os programas de carga } \\
\text { de dados e interface. Acompanha } \\
\text { todo o projeto para adquirir } \\
\text { conhecimento sobre o } \\
\text { funcionamento do novo sistema. }\end{array}$ \\
\hline $\begin{array}{l}\text { Suporte } \\
\text { Tecnológico }\end{array}$ & $\begin{array}{l}\text { Profissionais da área de Informática com } \\
\text { conhecimento das redes, bancos de dados e } \\
\text { sistemas operacionais em uso na empresa, } \\
\text { assim como da parte de configuração do } \\
\text { pacote a ser instalado. }\end{array}$ & $\begin{array}{l}\text { Instala os softwares necessários. } \\
\text { Dá suporte às redes, banco de } \\
\text { dados, acessos e autorizações. } \\
\text { Monitora e ajusta performance. }\end{array}$ \\
\hline
\end{tabular}

\subsection{Mudanças Organizacionais}

O mundo de hoje caracteriza-se por um ambiente em constante mudança. O ambiente que envolve as organizações é extremamente dinâmico, exigindo delas uma elevada capacidade de adaptação como condição básica de sobrevivência.

De acordo com Chiavenato (1999), enquanto a mudança genérica envolve alterações no ambiente em geral, a mudança organizacional é um conjunto de alterações estruturais e comportamentais dentro de uma organização.

Tomei (2002) acredita que a mudança estratégica envolve muitas ações e leva, em geral, anos para se realizar completamente. A mudança estratégica requer um re-pensamento das crenças básicas que a empresa possui para se definir e para realizar seu negócio. Essas crenças, ou seja, a cultura, levou 
muitos anos para se desenvolver. E esta mesma cultura pode ser o inibidor do sucesso de um processo de mudança se a empresa não conhecer sua cultura.

Nos itens a seguir, será utilizado o referencial teórico de Megginson (1998) sobre a mudança organizacional.

Inúmeros fatores afetam uma organização e a maioria deles está continuamente mudando. Essas forças que causam mudanças têm origem tanto dentro quanto fora da organização.

As forças externas têm um impacto maior na mudança organizacional do que os estímulos internos, pois, a administração tem pouco controle sobre eles. Uma organização depende e precisa interagir com o ambiente externo, se deseja sobreviver. Portanto, qualquer coisa que interfira ou modifique o ambiente pode afetar as operações da organização e causar pressão para mudança.

A mudança organizacional pode ocorrer por causa das mudanças nas variáveis externas, como sistemas políticos, econômicos, mercado, tecnologia e valores. Há uma variedade enorme de forças externas, desde descobertas tecnológicas até mudanças de estilo de vida, os quais fazem pressão em uma organização para mudar suas metas, estrutura e métodos de operação.

As pressões para mudança podem surgir também de dentro da organização. Essas forças internas de mudanças podem resultar de novos objetivos e ou culturas organizacionais, novas diretrizes, tecnologia ou atitudes dos empregados.

As forças externas e internas não se encontram isoladas, estão muitas vezes inter-relacionadas. "Se o nível de mudança de uma organização é menor que o nível de mudança externo, o final está à vista”, Jack Welch, ex-executivochefe da GE.

Há duas maneiras principais de lidar com a mudança organizacional. A primeira é o processo reativo, quando a organização se adapta aos poucos, para tratar os problemas à medida que eles surgem. A segunda é o processo proativo que envolve atos para mudar o status quo. "Toda mudança organizacional desafia a lei animal do menor esforço. Ainda que seja mudança comprovadamente para melhor", Gary Hamel, consultor inglês.

Devido à rapidez e a complexidade das mudanças no mundo de hoje os administradores devem compreender e usar a mudança organizacional planejada.

A idéia de que a mudança é um processo planejado corresponde à visão dominante nos estudos organizacionais. 
Em traços gerais, os modelos de gestão planejada consagram três fases principais: preparação, implementação e reforço da mudança.

A fase de preparação corresponde à identificação do ponto de chegada: o que se pretende dá mudança? A que direções ela deve conduzir a organização? Crucial nesta fase é a definição dos objetivos da mudança assim como a convicção de que ela é necessária.

Nutt \& Backoff (2001) reforçam a importância de uma visão de futuro que seja apelativa para os membros organizacionais, por eles percebida como realizável, e para a qual se sintam capazes de contribuir eficazmente. A definição dos objetivos deve ser acompanhada de um sistema de recompensas capaz de estimular a adesão dos trabalhadores.

Também é importante referir a necessidade de constituir um time poderoso que tenha capacidade de conduzir a mudança. Muitos esforços de mudança falham, de fato, porque aqueles que procuram levar a cabo não são capazes de constituir uma equipe suficientemente poderosa (persuasiva, eficiente, firme, empenhada) para ultrapassar as resistências decorrentes dos interesses pessoais.

A necessidade de os gestores deterem competências políticas para implementarem as decisões foi defendida por Pfeffer (1992) em "O processo de gestão / implementação da mudança - uma perspectiva baseada no poder da influência." No seu entender, tanto a via hierárquica como a estratégia de desenvolver uma cultura forte ou uma visão fortemente partilhada não são suficientes para tal implementação, sendo necessário recorrer a atuação política.

Segue os sete passos escritos pelo autor:

1. Decida quais são os seus objetivos, isto é, o que pretende alcançar.

2. Diagnostique os padrões de dependência e interdependência dos atores ( i.e.,indivíduos, unidades organizacionais, alianças )

3. Detecte os pontos de vistas desses atores, assim como o modo como tenderão a sentir-se perante a mudança que pretende implementar.

4. Compreenda quais são as bases de poder desses atores. Detecte quais são os que podem exercer mais influência (positiva ou negativa) no processo de mudança que deseja.

5. Diagnostique quais são as suas próprias bases de poder. Reflita sobre as que pode desenvolver para adquirir maior controle sobre a situação. 
6. Dada a situação que se depare, defina quais são as estratégias e táticas de influência mais apropriadas para que seu desejo de implementar a mudança seja bem sucedido.

7. Com o cenário assim desenhado, escolha o curso de ação que lhe permita alcançar as suas metas.

A implementação da mudança consiste na colocação em prática das ações necessárias para alcançar os objetivos estipulados. Ela inclui a comunicação da visão, a seleção dos recursos, a clarificação de responsabilidades, o apoio aos colaboradores em momentos de descrença e ceticismo, o empowerment dos colaboradores, e o controle do processo.

O reforço da mudança passa pela criação e divulgação de ganhos rápidos, mesmo que pequenos. A constatação, a curto prazo de resultados positivos, ainda que de pequena escala, gera entusiasmo e transmite a mensagem de que a mudança é um desafio exeqüível e compensador.

As mudanças planejadas, segundo Weik (2000), apresentam um conjunto alargado de vantagens e ao mesmo tempo seus inconvenientes, conforme quadro abaixo.

Quadro 3

\begin{tabular}{|c|c|}
\hline Vantagens & Inconvenientes/riscos \\
\hline $\begin{array}{l}\text { Focaliza a atenção nos objetivos que se pretendem } \\
\text { alcançar }\end{array}$ & O planejado nem sempre é implementado \\
\hline $\begin{array}{l}\text { Normalmente está alinhada com a distribuição do } \\
\text { poder, o que pode facilitar a sua implementação }\end{array}$ & $\begin{array}{c}\text { A informação pode ser distribuída assimetricamente } \\
\text { entre sub-unidades, assim formando perspectivas } \\
\text { diferentes do problema e do processo }\end{array}$ \\
\hline $\begin{array}{l}\text { Fornece uma aparência de racionalidade - daí lhe } \\
\text { podendo advir maior legitimidade }\end{array}$ & $\begin{array}{l}\text { Mais adequada para responder a ameaças do que para } \\
\text { a exploração de oportunidades }\end{array}$ \\
\hline $\begin{array}{c}\text { Permite uma análise comparativa das alternativas para } \\
\text { implementação, facilitando a escolha das mais } \\
\text { satisfatórias }\end{array}$ & $\begin{array}{c}\text { Pode induzir a adoção de práticas que funcionaram } \\
\text { bem noutros contextos - mas que não se adequam às } \\
\text { especificidades da organização }\end{array}$ \\
\hline $\begin{array}{c}\text { A via considerada mais adequada é mais facilmente } \\
\text { explicitada e transmitida }\end{array}$ & $\begin{array}{c}\text { Atrasos na implementação, impasses e lutas políticas } \\
\text { podem neutralizar a utilidade da mudança }\end{array}$ \\
\hline
\end{tabular}

A verdade, porém, é que nem sempre o planejado é implementado. Diversas razões ajudam a explicar essa discrepância. Por um lado, a informação pode ser distribuída assimetricamente, ou seja, diferentes partes da organização podem ter idéias e conhecimentos sobre o processo da mudança. Adicionalmente, todos aqueles que se sintam potencialmente prejudicados pela mudança tenderão a resistir. Segundo Prue \& Frederikson (1982), a ultrapassagem da resistência à mudança é um processo complexo cujo desfecho 
depende, designadamente, dos interesses dos contendores, do seu poder reativo e das táticas de jogo político que levam a cabo.

Abaixo, algumas potenciais razões, segundo Stanislao (1983), pelas quais as pessoas resistem à mudança:

Quadro 4

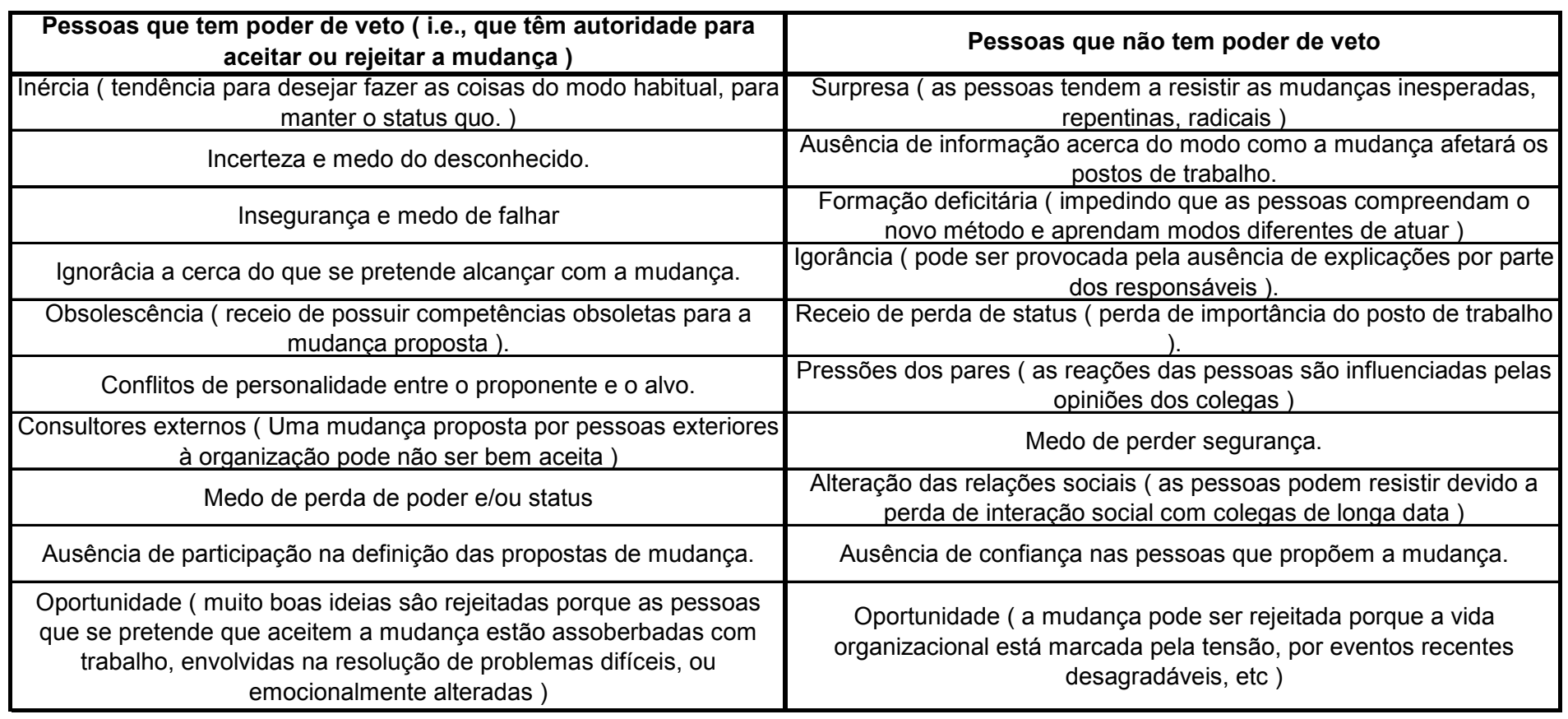

Gonçalvez (2003) aponta outras seis questões que marcam a resistência à mudança:

1. Preconceito com resultado: os membros afetados pela mudança tendem a fantasiar que as conseqüências serão sempre negativas.

2. Receio de mais trabalho: as pessoas ficam predispostas a pensarem que a mudança trará aumento na carga de trabalho e redução de oportunidades.

3. Necessidade de mudança de hábitos: exigência de mudança de hábitos que já estão internalizados.

4. Falha na comunicação: os membros da organização não são devidamente comunicados sobre os motivos da mudança e as expectativas que devem ser geradas em função dela.

5. Incapacidade de alinhar a organização como um todo, problemas para coordenar tudo que envolve a mudança, tais como, estrutura organizacional, sistemas, tecnologias, competências essenciais, conhecimento, cultura e habilidades de seus integrantes. 
6. Revolta por parte dos funcionários: é uma defesa criada pelos funcionários por existir uma percepção de que a mudança é uma imposição e, portanto, tira o controle das pessoas.

Por outro lado, ainda segundo Golçalvez (2003), existem algumas formas de neutralizar a resistência a uma mudança organizacional, das quais pode-se citar:

1. Criação da necessidade de promover a mudança: facilitar a compreensão das pessoas de que é preciso mudar, criando uma visão positiva sobre a forma como estas pessoas serão afetadas e que existe segurança quanto ao que está sendo feito para mudar.

2. Comunicação: é essencial ter uma comunicação eficaz e efetiva para a transmissão da importância da mudança.

3. Criação de uma aliança: importância de ter um grupo influente dentro da organização para promover a mudança.

4. Desenvolver a mudança em larga escala: a mudança faz a organização enfrentar questões mais profundas, como a cultura organizacional e, portanto, leva à mudanças reais e permanentes, uma vês que envolve os fundamentos da organização.

5. Promover a participação: incluir os funcionários nas decisões sobre o processo de mudança. Isso traz um maior comprometimento, pois ocorre uma consciência entre as pessoas de que elas tem influência nas decisões que envolvem os seus destinos e os da organização.

Porém, "Ninguém pode persuadir outra pessoa a se modificar. Cada um de nós toma conta da porta de mudança, que só pode ser aberta pelo lado de dentro. Não podemos abrir a porta de outra pessoa, seja por meio de argumentos ou pressão emocional", Stephen R. Covey, consultor NorteAmericano.

Contudo, a mudança organizacional continua sendo alvo das atenções dos executivos. A complexa e dinâmica realidade econômica, política, tecnológica e social que vivemos tem profundo impacto na forma de planejar, operar e administrar as organizações. A liberação econômica, a globalização crescente, a competição sem fronteiras, as privatizações, entre outros objetivos, levam ao processo inevitável de mudança e adaptação. O ambiente de trabalho, porém 
não pode sobreviver ao desafio de mudança constante sem uma estratégia adequada.

Paul Campbell Dinsmore, consultor especializado em Gerência de Projetos e Mudanças Organizacionais, é citado no artigo de Vanda Souza e recomenda alguns princípios da Gerência de Projetos tais como: Prazo / Custo / Qualidade / Pessoas. Baseada nesse princípio, Vanda Souza estabelece algumas fases fundamentais para o sucesso do processo de mudança.

1. Diagnóstico claro da situação: levantar dados e informações com o maior número de pessoas envolvidas no processo de mudança. Entender o projeto e seus objetivos.

2. Alinhamento dos objetivos: definição do escopo ou especificação funcional: qual o resultado final esperado? Devendo ser quantificado na medida do possível.

3. Fixar estratégia: estabelecer a metodologia geral ou plano básico para se implementar a mudança. Definir a política de utilização dos recursos internos e externos.

4. Fortalecimento da cultura organizacional: o desafio consiste na necessidade de construir uma nova cultura e/ou reforçar a cultura existente.

5. Comprometimento das pessoas com os objetivos e estratégia: o sucesso de tais mudanças depende da capacitação e preparação do pessoal, em todos os níveis, para enfrentar os novos desafios. É preciso ousar, arriscar e inovar para vencer. A preparação do pessoal para mudança exige uma abordagem inovadora que demonstre, através de vivência, como encarar o risco e desenvolver formas inovadoras de trabalho.

6. Identificar atividades: subdividir o projeto como um todo em "fases de trabalho", passíveis de serem gerenciadas e controladas.

7. Identificar recursos: determinar os recursos humanos disponíveis para implementar as mudanças, analisando a qualificação, tempo de utilização e quantidade requerida. Levantar também necessidades de recursos financeiros, materiais e equipamentos especiais.

8. Treinamento adequado das pessoas: é necessário adotar os programas de treinamento de conteúdo e metodologia, embasados em uma filosofia que devolva ao indivíduo a capacidade de pensar, a partir dos resultados da sua própria experiência. Isso implica em 
um processo de aprendizagem que é desenvolvido além da sala de aula, integrando técnicas e pensamento gerencial, intuição e intelecto, ciência e bom senso.

9. Estabelecer tempo para cada atividade: com base nos recursos, calcular o tempo de execução de cada atividade. Estabelecer calendário das atividades com datas programadas de início de término.

10. Rever tudo: ajustar as necessidades de prazo global com a disponibilidade de recursos, reavaliar a lógica, refinar o plano. Em todas as fases, o gerenciamento eficaz dos aspectos culturais e humano é a chave para o sucesso. O desafio e conseguir integrar a abordagem técnica da implementação com o desenvolvimento das competências humanas.

No mundo organizacional, a sobrevivência das empresas está intimamente relacionada com o processos de mudança. E a correta condução deste processo está intimamente relacionada a uma metodologia que garanta sua efetiva implementação. 


\section{Metodologia}

\subsection{Tipo de Pesquisa}

Segundo conceitos de Vergara (2000), essa pesquisa se classifica da seguinte maneira.

Quanto aos fins $\rightarrow$ Explicativa: pois tem como objetivo esclarecer quais fatores contribuem para o sucesso da implementação da mudança.

Quanto aos meios $\rightarrow$ Bibliográfica: pois é um estudo desenvolvido com base em material publicado em livros e artigos. Fornece instrumental analítico para outros tipos de pesquisa. Assim como é um estudo de caso: pois é circunscrito a uma empresa e tem caráter de profundidade e detalhamento.

\subsection{Coleta de Dados}

A coleta dos dados, que compõem o desenvolvimento dessa pesquisa, deu-se em duas etapas, descritas a seguir.

A primeira etapa, composta por uma pesquisa bibliográfica resumiu-se na busca por informações já publicadas para verificação de informações sobre mercado de sistemas ERP, decisões que levam os gerentes a optarem por adotar um software ERP, principais estratégias de implementação de tais sistemas, fatores críticos para o sucesso desse tipo de projeto, conceitos de administração de projetos e principalmente sobre mudanças organizacionais, para maior compreensão do tema proposto. Essa pesquisa foi realizada em livros, artigos e páginas da internet.

A segunda etapa da pesquisa foi feita na Ceras Johnson, por meio da utilização do material interno oferecido pela empresa que já implementou o sistema em outras subsidiárias. Essa pesquisa visa identificar aspectos sobre a maneira como a companhia planeja gerenciar essa mudança, ou seja, desde identificar as expectativas quanto ao projeto, suas principais etapas até o plano de OCM em si.

\subsection{Tratamento dos Dados}

Na primeira fase do projeto, o tratamento dos dados foi feito de uma forma qualitativa, pois as informações encontradas foram reunidas, analisadas e, logo após, expostos os princípios de diversos autores, conforme publicações em seus artigos e livros com dados pertinentes ao assunto. Os dados coletados por meio 
de pesquisa bibliográfica, serviram de base para o referencial teórico que contextualiza esse trabalho.

A complexidade e a abrangência dos dados exigiu a utilização de um método que possibilitasse a compreensão e tradução dos mesmos. Portanto, os dados coletados na pesquisa bibliográfica e na observação participativa foram tratados qualitativamente levando em consideração várias interpretações.

Como resultado dessa pesquisa espera-se uma compreensão maior do planejamento da mudanças como fator prioritário em relação à implementação de um novo sistema de gestão empresarial.

\subsection{Limitações do Método}

O método escolhido para o estudo apresenta certas limitação. Elas são apresentadas a seguir.

Apesar de se buscar nos trabalhos acadêmicos a neutralidade científica, talvez ela não exista, não por questões fraudulentas, mas porque os indivíduos que as realizam possuem percepções próprias, as quais podem acabar interferindo em seus trabalhos.

A metodologia escolhida para a pesquia poderá apresentar algumas dificuldades e limitações visto que o estudo se trata de um mercado muito específico e onde as informações não são de total acesso.

A pesquisa bibliográfica limitou-se a estudar o que entendedores do assunto dizem a respeito da mudança organizacional, prós e contras de seu planejamento, entre outros ligados ao assunto principal.

Já em relação à pesquisa na empresa, o método utilizado restringe-se ao material oferecido por uma única empresa, S.C. Johnson, objeto desse estudo.

A conclusão da pesquisa pode ser estendida às demais empresas localizadas no Brasil, assim como em empresas de outros países. No caso de utilização em outros países vale lembrar que a cultura brasileira é diferente e que a cultura da organização é um dos principais temas que devem ser levados em consideração no momento que se deseja realiza qualquer mudança. 


\section{Análise Crítica}

\subsection{A Empresa}

A empresa foi fundada nos Estados Unidos em 1886 por Samuel Curtis Johnson. Samuel que na época era vendedor de pisos "parquet" de uma loja de ferramentas e que em seguida comprou o estabelecimento do qual era empregado. Algum tempo depois, incentivado pelos pedidos de seus clientes, passa a desenvolver produtos para a conservação dos pisos. Logo, o faturamento com a venda de ceras, supera a venda dos pisos.

Assim nasce a SCJ - Samuel Curtis Johnson, empresa familiar, dirigida a cinco gerações pelo clã Johnson.

Samuel começou sua carreira profissional na cidade de Kenosha, Wisconsin, EUA vendendo quadros, molduras, livros, papéis de parede, cortinas, etc. Até dez anos mais tarde fechar esse negócio e começar a produzir e vender assoalhos de tacos em lindos desenhos geométricos, tão populares naqueles dias. Levou seu filho para trabalhar com ele e organizou, em Racine, Wisconsin a companhia que eventualmente tornou-se a S.C. Johnson \& Son.Inc.

Quase todas as vezes em que vendia um assoalho, seus fregueses the perguntavam como mantê-lo em boa aparência.

Dentro de pouco tempo, esta solicitação tornou-se quase uma exigência entre os fregueses, então Samuel começou a pensar em produzir um polidor de assoalho como uma "linha secundária".

Ele sabia que existia muitos belos e antigos assoalhos de madeira em excelentes condições nas mansões e castelos na Europa, alguns com 200 ou 300 anos e que nunca haviam sido tratados com qualquer outra coisa que não fosse cera. Com isso em mente ele preparou e vendeu um polidor de assoalho feito com cera. Uma das ceras que ele usava era a da Palmeira da Carnaúba, que nasce no América do Sul, mais especificamente no Brasil. Ela era mais dura que a cera de abelha e dava mais brilho à madeira.

Em pouco tempo, a "linha secundária" de polidor de cera, iniciada na década de 1890, transformou-se na parte principal do negócio.

Em 1919, após o falecimento de Samuel, seu filho Herbert F. Johnson passou a ser o presidente da companhia. Com seus sábios conselhos e liderança energética, a companhia cresceu até se tornar a líder mundial em produção de polidores feitos a partir da cera, para assoalhos e móveis. 
Em 1922, depois de se formar na Universidade de Cornel, o neto de Samuel e filho de Herbert foi trabalhar no laboratório de Química da companhia e ficou instantaneamente interessado na cera carnaúba.

Olhando para o futuro, via que seria vantajoso para a indústria da cera estudar esta matéria prima em sua origem, no Brasil. A partir daquele instante, começou a ansiar pelo momento em que pudesse empreender uma expedição ao Brasil, com este propósito.

Em 1935, seus planos tornaram-se realidade e organizou e liderou a Expedição da Carnaúba, de avião até o Brasil.

Assim começou uma longa história que estreitou o relacionamento com o Brasil e com a hoje existente subsidiária brasileira.

A companhia está presente com subsidiárias instaladas em mais de cem países comercializando como líder mundial, produtos de higiene pessoal, limpeza, inseticidas e armazenamento doméstico em mais de cento e quarenta países.

No Brasil, a subsidiária foi instalada em 1960 no Rio de Janeiro onde se localizam a fábrica e o escritório central, tendo também escritório e centro de distribuição em São Paulo.

A empresa comercializa linhas de produtos similares aos da companhia Norte Americana, com adaptações ao mercado local, atuando em diversas categorias e marcas conhecidas em todo país.

Figura 2

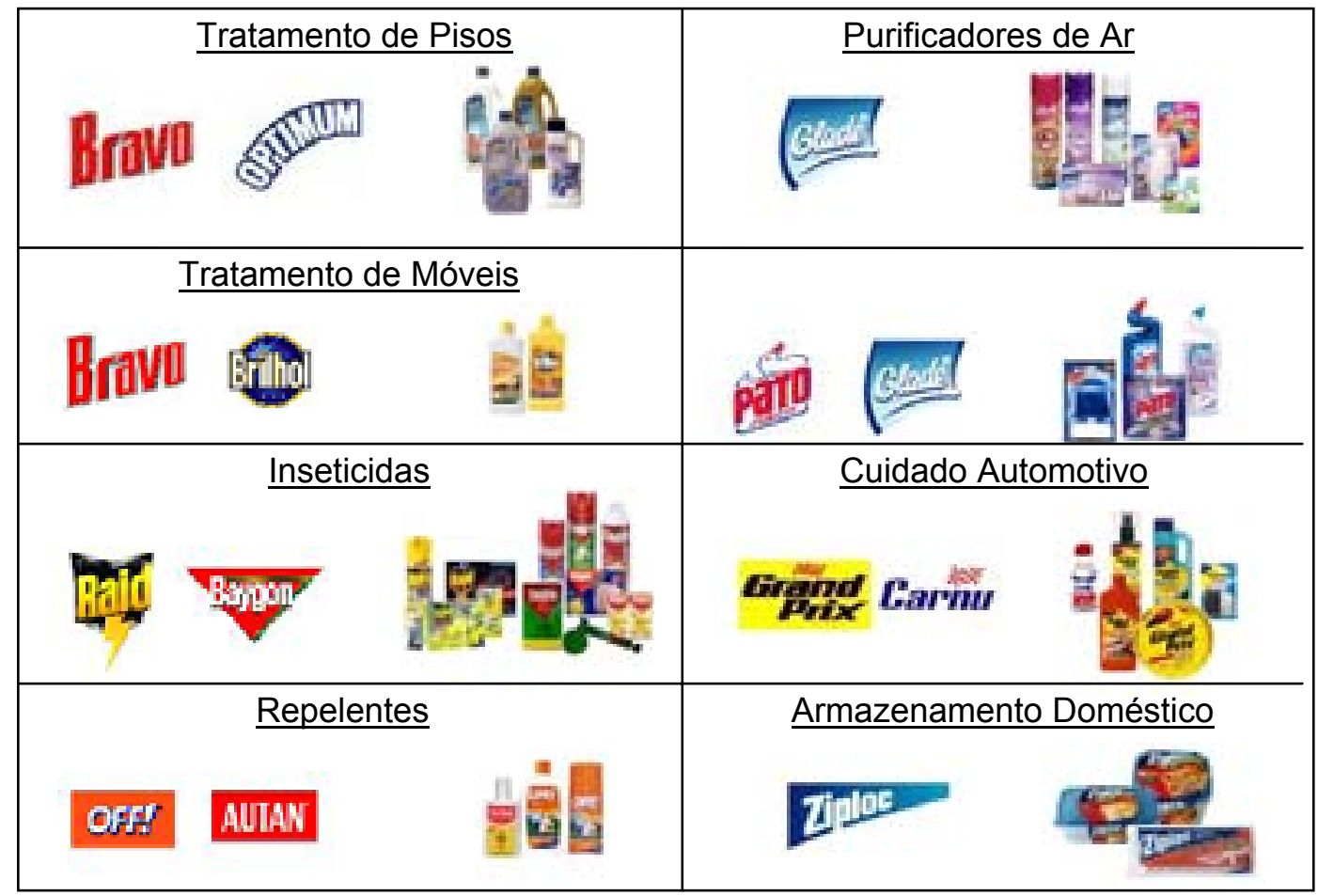


Tem como missão ser uma companhia líder no mercado de produtos domésticos especializados, desempenhando papel de crescimento prioritário direcionado pelas estratégias globais.

Sua visão é tornar-se a maior subsidiária das Américas ( Sul / Central ) como primeiro passo para tornar-se uma companhia de ponta no Brasil.

A filosofia da Johnson é baseada "No que acreditamos".

- Nossos funcionários:

Nós acreditamos que a vitalidade e a força fundamentais de nossa companhia em todo mundo reside em nosso pessoal.

- Nossos consumidores:

Nós acreditamos na conquista de confiança duradoura dos consumidores usuários de nossos produtos e serviços.

- Nossos relacionamentos:

Nós acreditamos na contribuição para o bem estar dos países e das comunidades onde mantemos negócios.

- Nossa qualidade de vida:

Nós acreditamos no aprimoramento do entendimento mundial.

\subsection{O que é o Projeto?}

O projeto chamado Global One é um dos projetos mais importantes da história da Johnson. Com um orçamento de US\$127 MM, é o quarto maior investimento da história da Companhia e o maior sem contar aquisições de marcas e fusões. O seu objetivo é padronizar todos os processos de negócios da Companhia em escala global, em vinte e oito países, através da implementação do SAP R/3, um sistema do tipo ERP. Com esse sistema, toda a eficiência operacional da Companhia será otimizada.

Através da implementação desse projeto, será possível ter uma visão ampla e consolidada da Companhia, de seus clientes, usuários e fornecedores, reduzindo a dispersão da informação.

Para trabalhar nesse desafio, há uma equipe global, regional e local, composta de funcionários e consultores para implementar o projeto em todas as áreas.

O Projeto Global One chegou, em novembro de 2004, à subsidiária brasileira da Johnson. Nesse projeto, a Johnson Brasil terá todos os seus processos de negócios padronizados, através da implementação compartilhada do SAP R/3. 
Figura 4

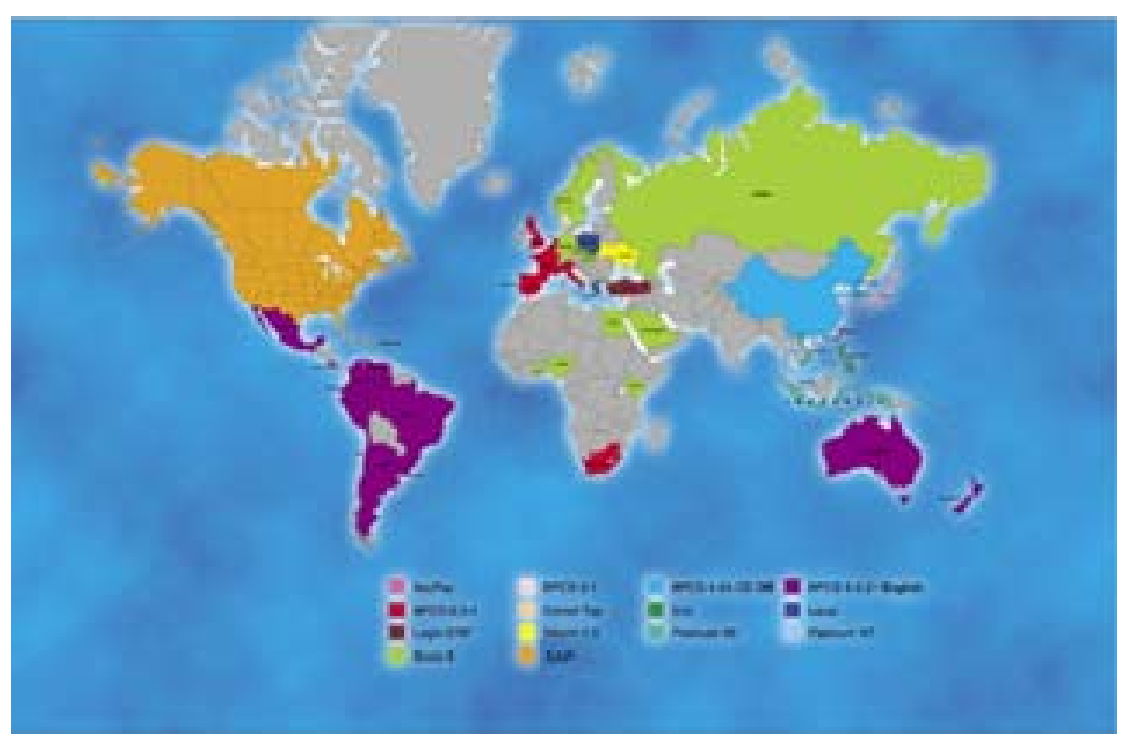

$\mathrm{Na}$ visão da SCJ, o Global One tem a ver com trazer para a SCJ dados globalizados através da padronização dos processos de negócios e da implementação de ERP comuns em suas maiores companhias. Segundo o presidente da subsidiária Brasileira, "O Global One não é apenas a instalação de um software, é uma iniciativa de negócios fundamental, que vai transformar a nossa maneira de fazer negócios".

No plano de negócios para 05/06 ( ano fiscal da SCJ ), a $1^{\text {a }}$ prioridade é a execução bem sucedida do Global One, na frente de objetivos como lucratividade, atendimento a clientes, crescimento de volume, e ganho de participação de mercado.

O projeto é dividido em quatro processos:

Finance - Onde são envolvidas as transações financeiras que sustentam o negócio.

Forecast to Stock - Parte que vai desde a previsão da demanda dos clientes até a disponibilidade dos produtos nos estoques.

Order to Cash - Parte que abrange desde a entrada dos pedidos dos clientes até a verificação dos pagamentos correspondentes.

Organizational Change Management - Comunicação, treinamento e gerenciamento da mudança em cada um dos três processos.

A figura abaixo ilustra o organograma do projeto. 
Figura 5

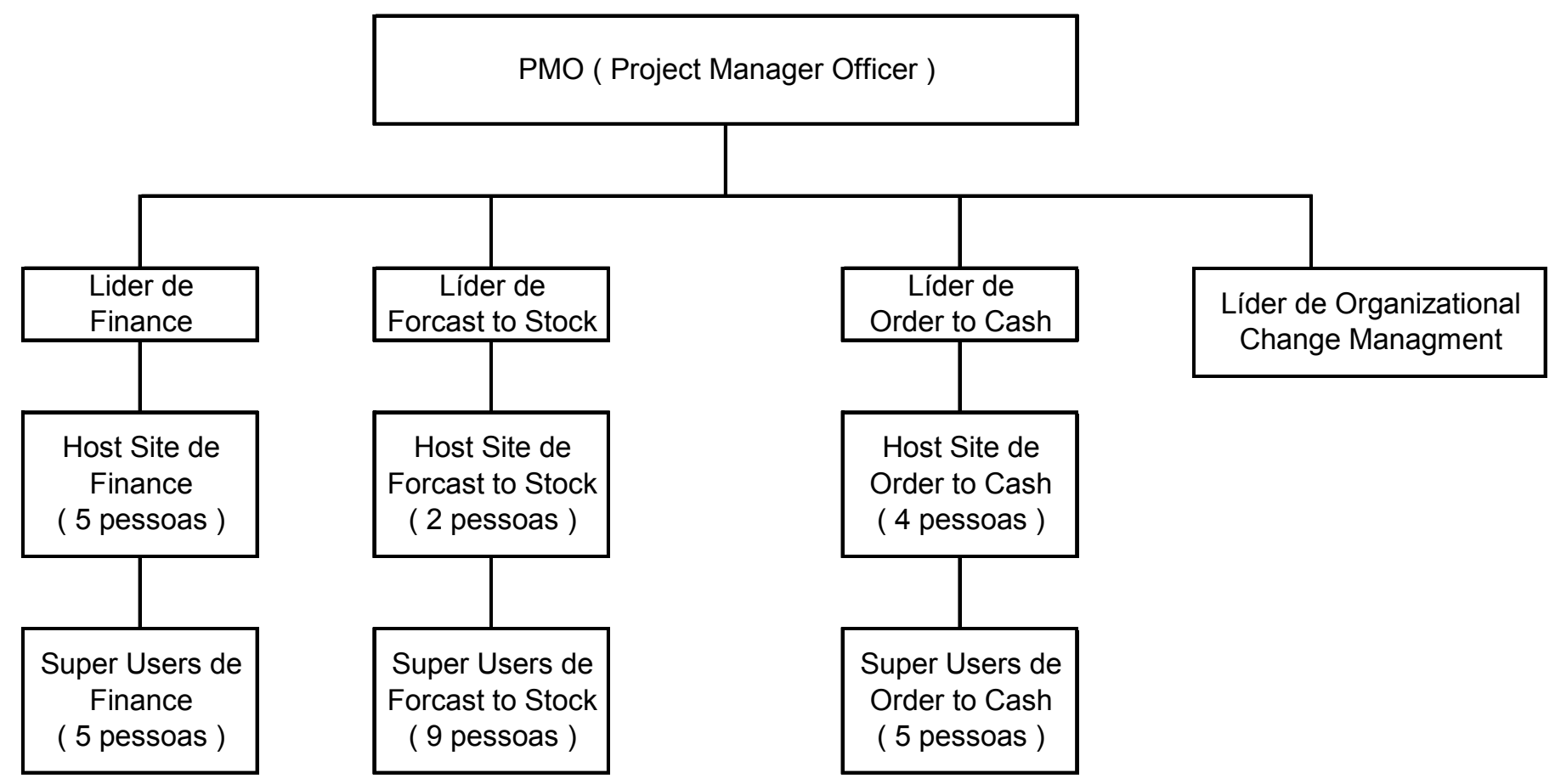

A hierarquia é dividida em quatro níveis:

Super Users - São os funcionários que faziam parte do negócio local e que de acordo com os seus altos conhecimentos nas suas áreas de orígem foram selecionados a particitar do projeto como os principais entendedores do negócio. São normalmente funcionários experientes e contratados a muito tempo que dentro de suas áreas concentram os maiores conhecimentos específicos de cada sub processo.

Host Site - São gerentes selecionados para gerenciar as equipes de super user.

Líderes - São gerentes seniors responsáveis por cada um dos quatro processos.

PMO - Líder do projeto no Brasil.

Foram contratados substitutos para cobrir as posições chaves deixadas pelas pessoas escolhidas para participar do projeto, garantindo a continuidade dos negócios durante a implementação.

Segundo o líder de Finance, Felipe Cohen: "O Global One é fundamental para manter a competitividade da Johnson em um mundo cada vez mais globalizado. Para ser bem sucedido, o Projeto vai exigir o esforço de todos, já que seu impacto será amplo e afetará todas as áreas da Companhia." 
Segundo o líder de OCM, André Santos: "A Companhia está investindo pesado na busca por maior competitividade e eficiência. Sem dúvida, isto irá contribuir de forma significativa para o sucesso da organização. Tenho certeza que o time da Johnson Brasil irá realizar esta mudança de forma engajada e comprometida, ou seja, com muito sucesso!"

Segundo o líder de Projeto, Carlos Tocantins: "O Projeto Global One é o grande desafio do ano para todos nós. Implementaremos o SAP e mudaremos substancialmente nossa forma de trabalhar. O SAP permitirá uma integração maior entre as áreas e com outras subsidiárias gerando benefícios como a diminuição da carga de re-trabalho e redução do capital de giro e de custos."

Segundo o líder de Forecast to Stock, Pedro Oliveira: "Expectativa e orgulho enormes de participar de um projeto tão grande e ambicioso, com resultados realmente significativos para a Companhia. Com o Global One, palavras como globalização e regionalização assumem significados mais palpáveis no negócio como um todo. Formamos um time de respeito, que estará literalmente suando a camisa para mais uma implementação de sucesso."

Segundo o líder de Order to Cash, Alexandre Hartmam: "Participar desse Projeto é uma grande oportunidade para o desenvolvimento pessoal e profissional."

Fisicamente aconteceram algumas mudanças no escritório para alocar os funcionários que estão diretamente ligados ao projeto.

A parte que era inicialmente ocupada pela área de sistemas, com a chegada do Global One esse espaço está sedo utilizado por toda a equipe participante do projeto, enquanto os funcionários que continuaram dando procegumento ao dia a dia da empresa foram todos re-locados para a esquerda do escritório.

\subsection{Expectativas do Projeto.}

Como o projeto já foi implementado em dezessete países onde a Johnson atua já existe um modelo pré-fixado para a implementação.

Portanto, mudanças no modelo inicial não são esperadas e encontram resistências, pois o plano já foi testado e sabe-se que funciona. O chamado Global Template, é dito como forte e estável, e somente serão aceitas modificações de natureza legal ou impeditivas para os negócios. A tecnologia e as ferramentas que são utilizadas estão completamente desenvolvidas e integradas ao modelo. Qualquer mudança necessária para um determinado pais vai afetar todos os outros. 
Ponto de Partida ( Global template )

Figura 6

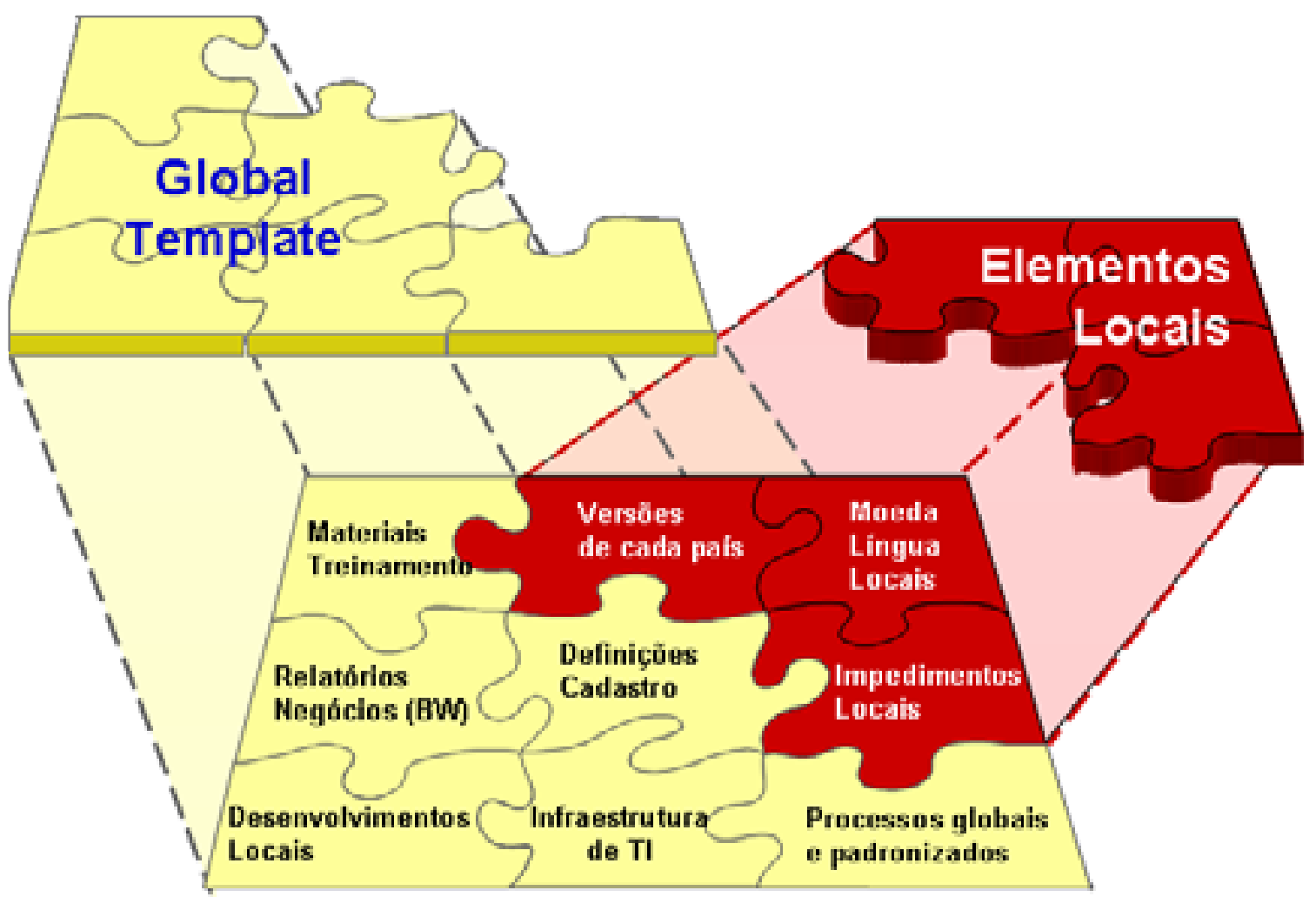

A parte amarela é um conjunto comum de processos padronizados junto à definição de dados que está sendo implementado em todos os países, enquanto a parte vermelha são os elementos locais que vão sendo adicionados a cada implementação (ex. Idioma, moeda, requerimentos legais, nomes e descrições locais).

O Template Global contém 61 sub-processos, 1.285 transações, 160 relatórios, 750 instruções de trabalho, visão geral de 55 sub-processos, 70 quick cards (cartões de consulta rápida) além de uma nova funcionalidade para vendas padronizadas entre companhias e para exportação, processo eficiente de picking, carregamento de caminhões mais flexível, processamento de vendas para entrega futura (backorder), administração de vendas em consignação, análise de lucratividade, tesouraria, administração de depósitos com estoque excedente, administração simplificada de sub-contratos, administração de depósito por rádio-frequência e indicadores chaves de performance globais. 


\subsection{Principais Etapas}

Figura 7

ONDA 3 - ETAPAS PRINCIPAIS

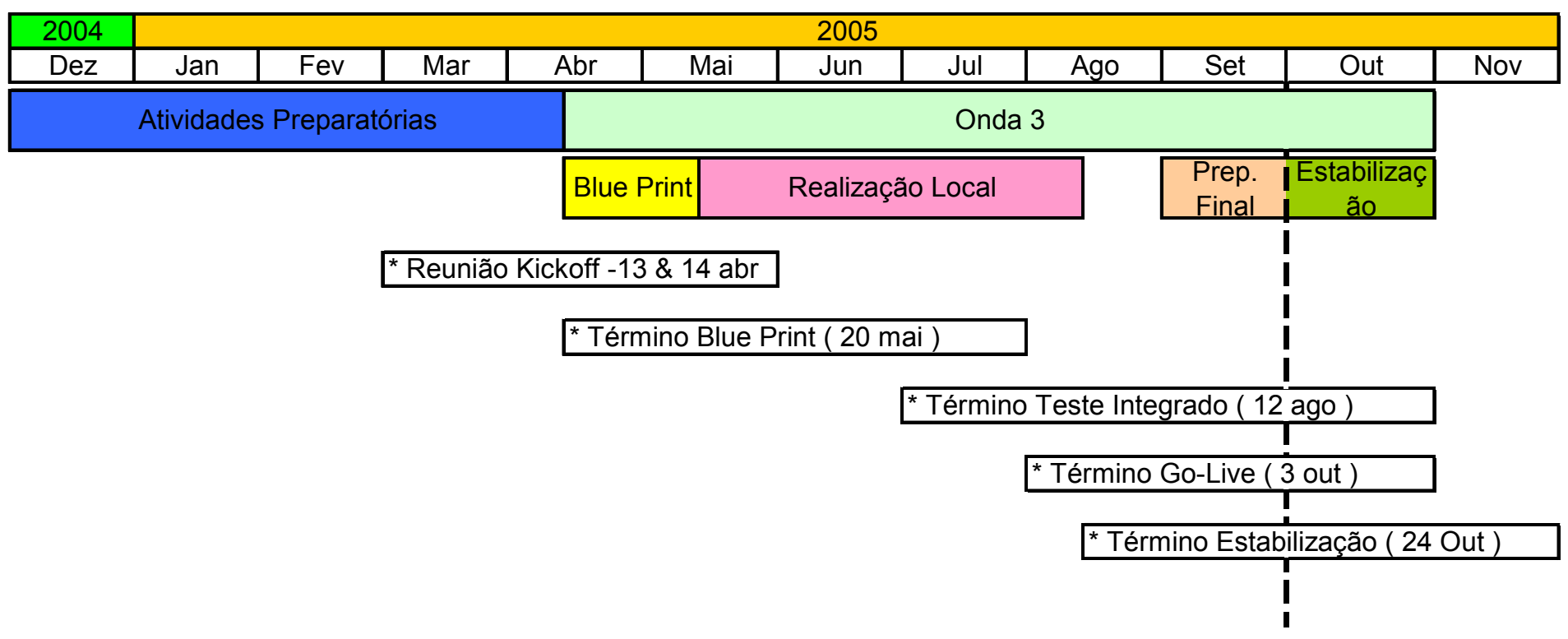

Atividades Preparatórias:

1. Planejamento de Recursos

2. Construção da Area do Projeto

3. Planejamento de Redução de Riscos

4. Limpeza do Cadastro

5. Identificação de Solução de Gaps no Pré-Blueprint

A reta final das atividades preparatória é o Warm-up que tem como objetivo esquentar os motores. A idéia é deixar toda a equipe alinhada e integrada para o início dos trabalhos. Acontece a apresentação das equipes, definição dos papéis e responsabilidades de cada um, cronograma e metas do projeto.

Blueprint Local

1. Identificar Gaps Locais

2. Resolver Gaps

Essa é a principal etapa do processo, pois é o momento em que se realizam workshops sobre os sub-processos para transferir conhecimento e identificar gaps entre as exigências locais e o modelo padrão (Global Template) 
e também é o momento de apresentar protótipos de soluções. Nessa etapa os membros do time do projeto também já iniciam a adaptação dos materiais de treinamento.

Todos os gaps são registrados no JIMS ( Johnson Issue Management System ), ferramenta usada para gerenciar e rastrear questões e gaps do projeto.

Os chamados Gaps são todos os possíveis problemas encontrados entre o modelo global e as exigências locais que poderão se tormar impeditivos para implementação caso não sejam avaliados e solucionados via adaptações ao modelo ou adaptações ao modo de gerenciamento do negócio.
Realização Local
1. Configurar o SAP
2. Transferência de Conhecimento
3. Teste Unidade
4. Teste Integrado

Nessa etapa acontece o teste detalhado na unidade da transferência de conhecimento e da unidade do template através da simulação de diversos cenários possíveis. Configuram-se as soluções de teste e a avaliação local de impacto organizacional é conduzida. Portanto, é o momento de demonstrações práticas da funcionalidade do sistema.

\section{Estabilização \\ 1. Treinamento do Usuário Final \\ 2. Prática do Go-Live \\ 3. Suporte}

Nessa etapa acontece o ensaio geral, o planejamento final da migração, o carregamento de dados e o treinamento dos usuários finais.

Após o Go-Live (momento em que o sistema antigo é desligado e o SAP começa a funcionar), os participantes do projeto começam a voltar às funções habituais, mas ao mesmo tempo estão responsáveis por resolver as questões conforme necessário e continuar a dar suporte aos usuários. 
Um projeto desse porte requer muito planejamento. Por isso é importante saber quais as ações irão acontecer na Johnson em cada dia da implementação. Para isso foi desenvolvido um plano específico que cobre cada uma das vinte e seis semanas do Projeto:

Figura 8

ONDA 3 - PLANO DE 26 SEMANAS

\begin{tabular}{|c|c|c|c|}
\hline FASE & DATAS & SEM. & ATIVIDADES \\
\hline \multirow{7}{*}{ BLUEPRINT LOCAL } & 4/4/2005 & -1 & On-Boarding Session ( Racine ) \\
\hline & $4 / 11 / 2005$ & 0 & Sessões de Kick Off dos Host Sites / Treinamento de Navegação \\
\hline & $4 / 18 / 2005$ & 1 & \multirow{5}{*}{$\begin{array}{l}\text { Transferência de conhecimento do Global Template, identificação de gaps legais/estatutárias e impeditivas, criando protótipos de soluções, preparação e aprovação do ADR, } \\
\text { preparação das especificações funcionais de ADS, ratificação do projeto, gap BW, super user / usuários finais identificados por subprocessos. }\end{array}$} \\
\hline & $4 / 25 / 2005$ & 2 & \\
\hline & $5 / 2 / 2005$ & 3 & \\
\hline & $5 / 9 / 2005$ & 4 & \\
\hline & $5 / 16 / 2005$ & 5 & \\
\hline \multirow{12}{*}{ REALIZAÇÃO LOCAL } & $5 / 23 / 2005$ & 6 & Kick-Off Treinamento / Configuração e Teste da Unidade \\
\hline & $5 / 30 / 2005$ & 7 & Configuração, Teste da Unidade \& Transf. Conhecimento, Mapeamento dos dados. \\
\hline & $6 / 6 / 2005$ & 8 & Configuração, Teste da Unidade \& Transf. Conhecimento, Mapeamento dos dados, ADS's terminados p/ teste integrado. Guias de transição adaptados localmente. \\
\hline & $6 / 13 / 2005$ & 9 & Configuração, Teste da Unidade \& Transf. Conhecimento, Mapeamento dos dados, Custo de projetos carregado. \\
\hline & $6 / 20 / 2005$ & 10 & Configuração, Teste da Unid. \& Transf. Conhec., Cronograma completo do Teste Integrado, adaptação local da segurança, prática de custos de prod., solução gaps BW. \\
\hline & $6 / 27 / 2005$ & 11 & Configuração, Teste da Unid. \& Transf. Conhec., Atributos MD congelados, solução gaps BW. \\
\hline & $7 / 4 / 2005$ & 12 & Teste da Unidade, carregamento de dados para teste integrado, análise de impacto organizacional, custo de prod. p/ teste integrado. \\
\hline & 7/11/2005 & 13 & Teste da Unidade, arquivo material driver congelado, custo para teste integrado, análise de impacto organizacional, treinamento dos instrutores. \\
\hline & $7 / 18 / 2005$ & 14 & Teste integrado / Teste de Stress \\
\hline & $7 / 25 / 2005$ & 15 & Teste integrado / Teste de Stress \\
\hline & $8 / 1 / 2005$ & 16 & Teste integrado / Teste de Stress / Iniciar teste de EC em scala total. \\
\hline & $8 / 8 / 2005$ & 17 & Teste integrado / Teste de Stress / Completar exercicios de treinamento. \\
\hline & $15 / 08$ a $28 / 08 / 05$ & & INTERVALO \\
\hline \multirow{5}{*}{ PREPARAÇÃO FINAL } & $8 / 29 / 2005$ & 18 & Treinamento de usuário final, ensaio geral do Go-Live, ensaio geral do carregamento de dados, Ensaio geral para custo de produtos. \\
\hline & $9 / 5 / 2005$ & 19 & Treinamento de usuário final, ensaio geral do Go-Live, Cutover plan completo, Ensaio geral de custo de produtos. \\
\hline & $9 / 12 / 2005$ & 20 & Treinamento de Usuário Final \\
\hline & 9/19/2005 & 21 & Treinamento de Usuário Final, mover config. para prod., carregar dados e custo de produto em prod. \\
\hline & 9/26/2005 & 22 & Treinamento de Usuário Final, carregar dados e custo de produtos em prod. \\
\hline \multirow{4}{*}{ SUPORTE GO-LIVE } & $10 / 3 / 2005$ & 23 & GO-LIVE \\
\hline & $10 / 10 / 2005$ & 24 & Estabilização \\
\hline & $10 / 17 / 2005$ & 25 & Estabilização \\
\hline & $10 / 24 / 2005$ & 26 & Término / Entrega ao COE Regional / Global. \\
\hline
\end{tabular}

\subsection{Liderança do Projeto}

O enfoque de gerenciamento de implementação envolverá dois grupos de gerenciamento distintos:

1 - Steering Committee

É responsável pelo gerenciamento detalhado da implementação e dos resultados esperados associados a ela.

Função:

Responsável pela direção local do projeto, garantindo que as metas e os objetivos sejam alcançados.

Responsabilidades:

- Solução de questões e minimização de riscos.

- Atuar dentro da comunidade do negócio como promotor do projeto, comunicando e habilitando os objetivos do programa.

- Aprovar o término de cada etapa principal do projeto inicial.

- Aprovar mudanças nos recursos do projeto inicial de origem local e no plano do projeto local.

- Os General Managers atuam como ligação regional chave e conexão com o management committee local. 
Os membros são os líderes regionais e globais do projeto.

2 - Equipe de Liderança

Fornece uma conexão direta com as equipes do Country Managment para garantir que os propósitos e objetivos das atividades iniciais em cada local sejam cumpridos, além de oferecer um fórum para solução de questões.

Função:

Responsável pela coordenação das atividades da equipe de implementação, para garantir a finalização bem sucedida de todos os resultados esperados do projeto.

Responsabilidades:

- Rastrear o progresso vs. Plano de atividades do projeto.

- Identificar divergências do plano do projeto e tomar ações corretivas.

- Solução de questões, alocação de recursos e priorização de atividades.

- Alertar o Steering Committe da Onda 3 sobre quaisquer riscos ao plano do projeto.

- Coordenar as atividades de todas as equipes de processos, tecnologia e mudança organizacional.

Os membros são os líderes de processos locais e regionais.

\subsection{Transferência de Conhecimento}

Esse é o processo utilizado para transferir as habilidades e o conhecimento necessários dos consultores da Deloitte para o time central do GO para os membros do Host Site da SCJ e para os Super Users.

Abaixo estão ilustrações da cronologia de transferência de conhecimento e algumas atividades que contribuirão para o conhecimento. As figuras a seguir ilustram o ciclo de transferência de conhecimento. No início desse ciclo os consultores estão com um nível de conhecimento e habilidades maior que o dos super users e host sites, de acordo com o passar das atividades do Global One e através de workshops de transferência de conhecimento, esses conhecimentos são divididos com os super users da mesma maneira que os super users tranferem seus conhecimentos do negócio para os consultores. No final do cilclo todos chegam ao mesmo nível de conhecimento, seja ele técnico ou do negócio. 
Figura 9

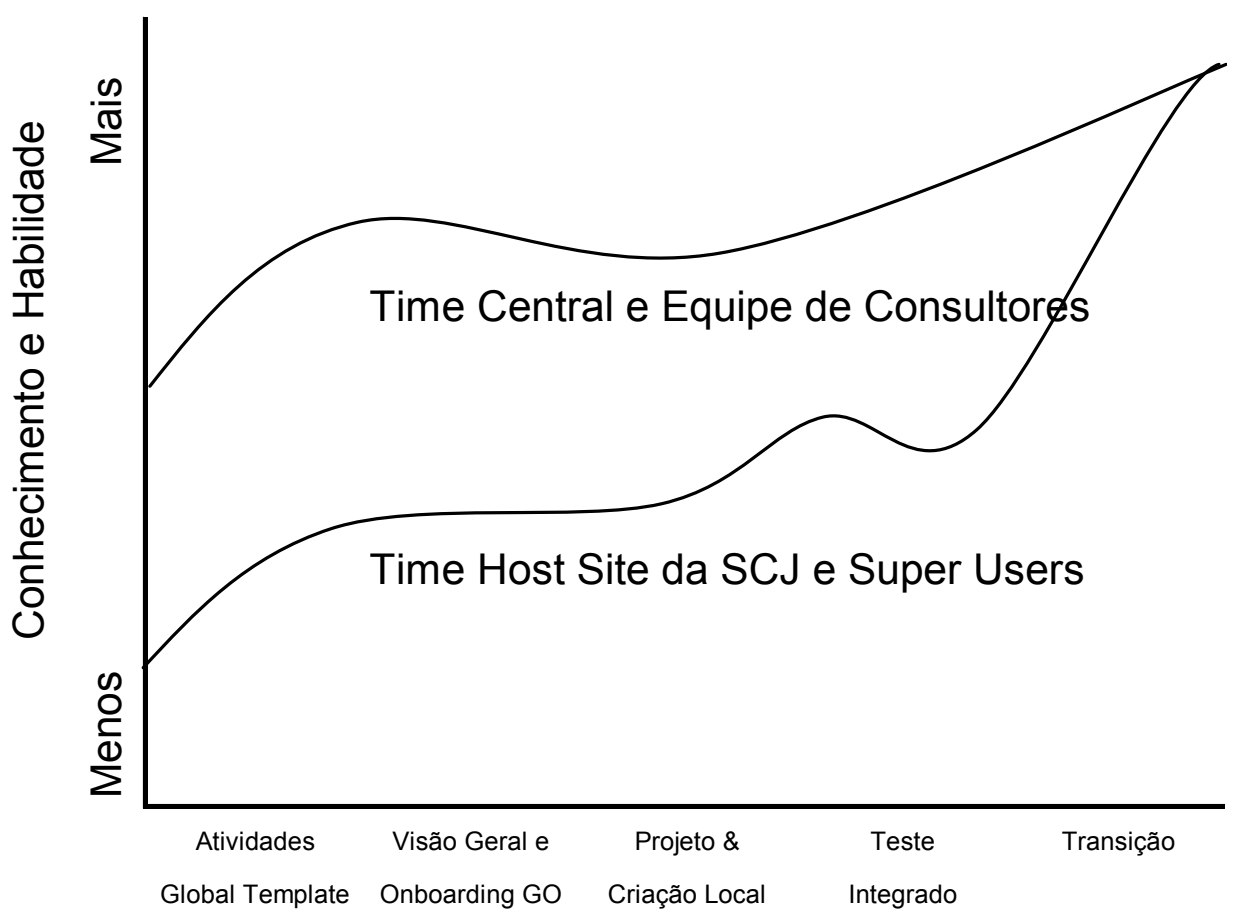

Cronologia da Transferência de Conhecimento

Figura 10

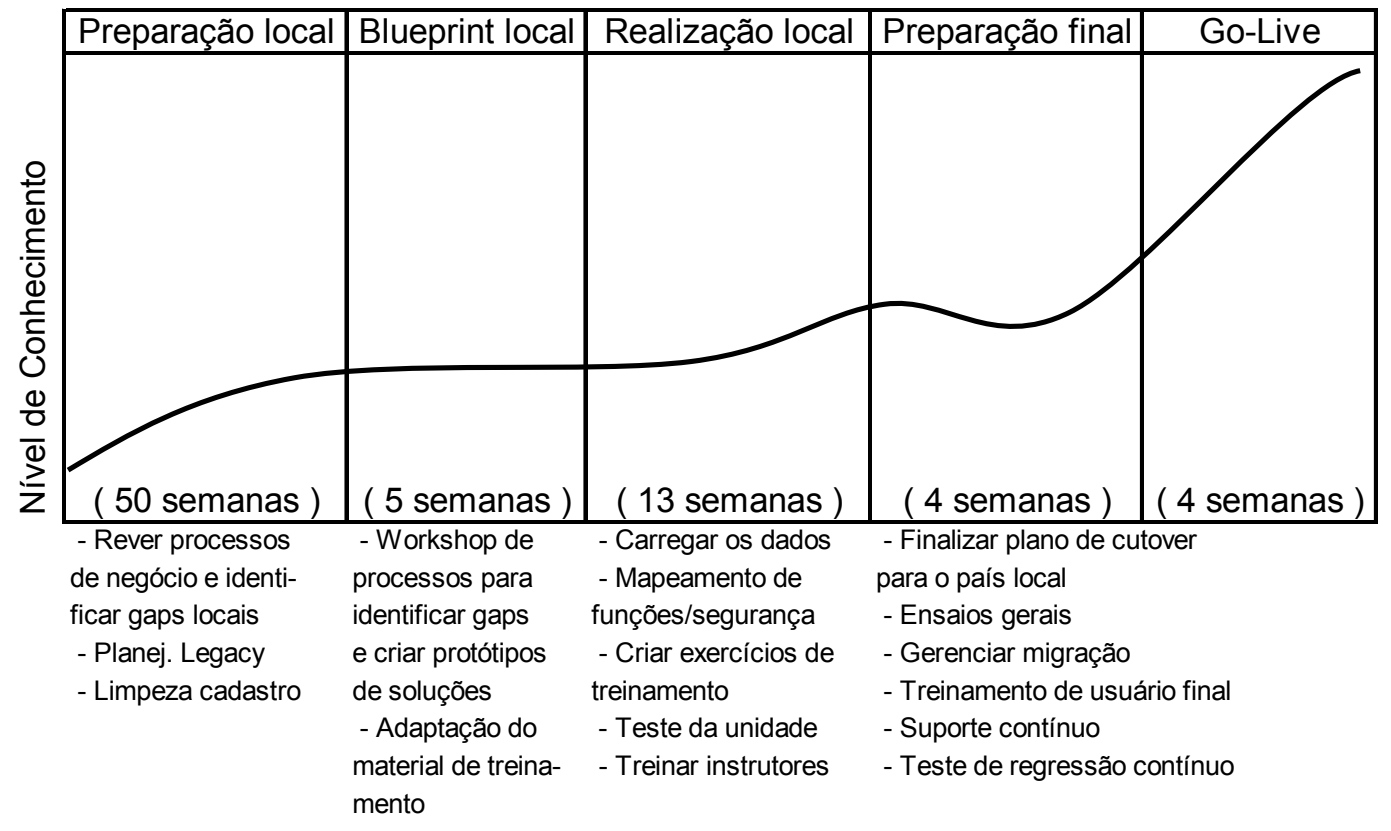

Atividades Global One 


\subsection{Comunicação}

Pessoas de 13 nacionalidades estão trabalhando no projeto no Brasil, 7 línguas estão sendo faladas, o que requer uma preocupação especial quanto a comunicação que é um fator muito importante para o sucesso do projeto.

Preocupações com o fato da equipe estar trabalhando com várias diferentes pessoas de diferentes países com diferentes línguas, tentando encontrar termos comuns para chegar a um entendimento, além de trazerem suas próprias normas culturais sobre comunicação e o fato de existirem diversas normas culturais que influenciam o comportamento requer que todos sejam sensíveis às variações que todos trazem para a equipe.

Para uma comunicação efetiva é necessário deixar claro para todos do grupo os diferentes estilos e preferências na solução de conflitos, criar uma norma que declare que o conflito é uma parte normal de qualquer ambiente de trabalho e que resolvê-lo exige concessões de todas as partes e a participação de todos.

O fato da equipe também ser virtual, trabalhando via WebEx, telefone, email exige ainda mais confiança e comunicação do que as equipes situadas no mesmo local. Um problema comum citado por muitos gerentes é a quebra de confiança que acontece quando os empregados não conseguem ver uns aos outros e se os membros da equipe têm dificuldade de alcançar-se mutuamente por telefone ou se não recebem respostas de seus faxes ou emails, é de natureza humana achar que alguém não está demonstrando dedicação suficiente ou não dá importância ao projeto. Portanto é importante que os gerentes desenvolvam estratégias de comunicação para manter os membros das equipes informados.

Um ponto chave para a formação de uma equipe virtual efetiva é confirmar o recebimento da comunicação, conforme a ilustração a seguir. 
Figura 11

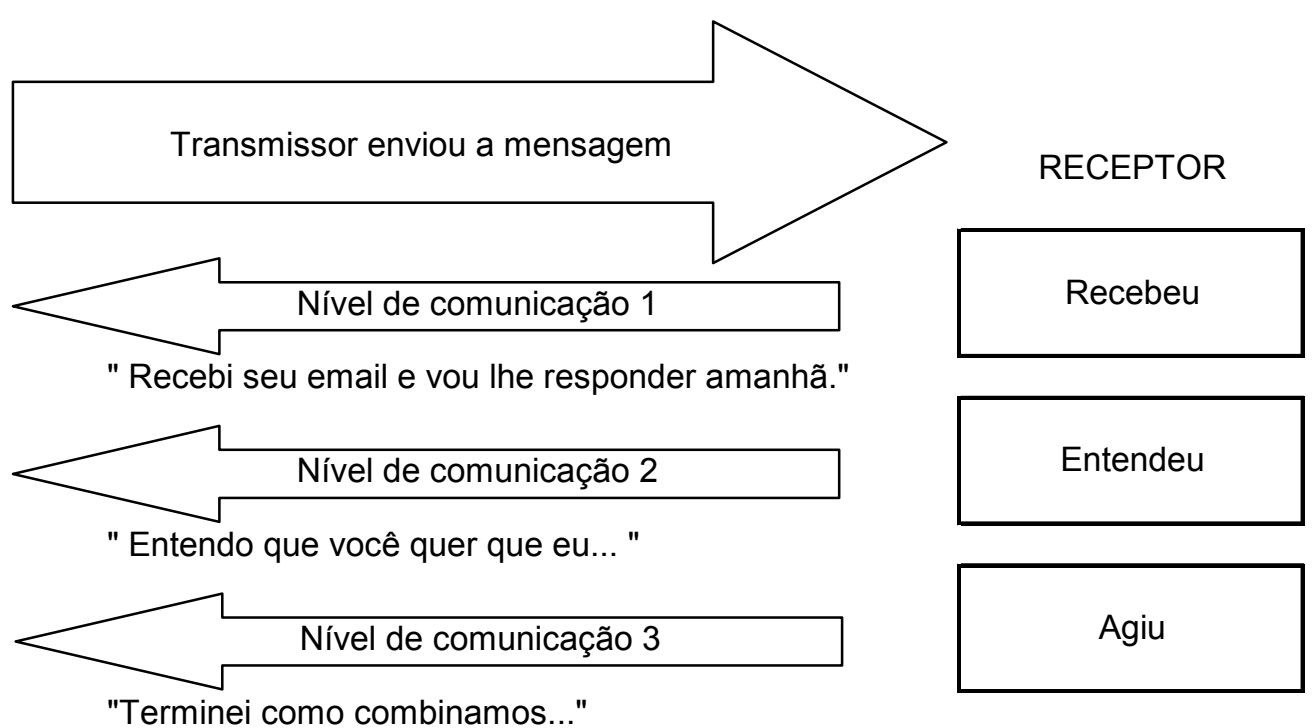

Um dos objetivos da comunicação é conduzir os principais envolvidos pelas mudança no tempo certo assim como dar informação correta no tempo certo, evitar sobrecarregar pessoas com informações e minimizar as confusões e mal-entendidos.

A figura abaxo ilustra através de um gráfico três momentos através do tempo em que o comprometimento dos envolvidos vai aumentando conforme a comunicação é efetuada.

O primento momento é o que chamam de consciência (azul), que é quando as pessoas já ouviram falar do Global One e já tem consciência do escopo básico e da visão do Global One.

No segundo momento, o entendimento, (amarelo) as pessoas compreendem o impacto da mudança para a sua equipe e tem entendimento pessoal de como seu trabalho vai mudar.

Finalmente no terceiro momento (vermelho) as pessoas desejam trabalhar e aprender com os novos processos, procedimentos e políticas e já possuem as habilidades e a capacidade de operar no novo ambiente. 
Figura 12

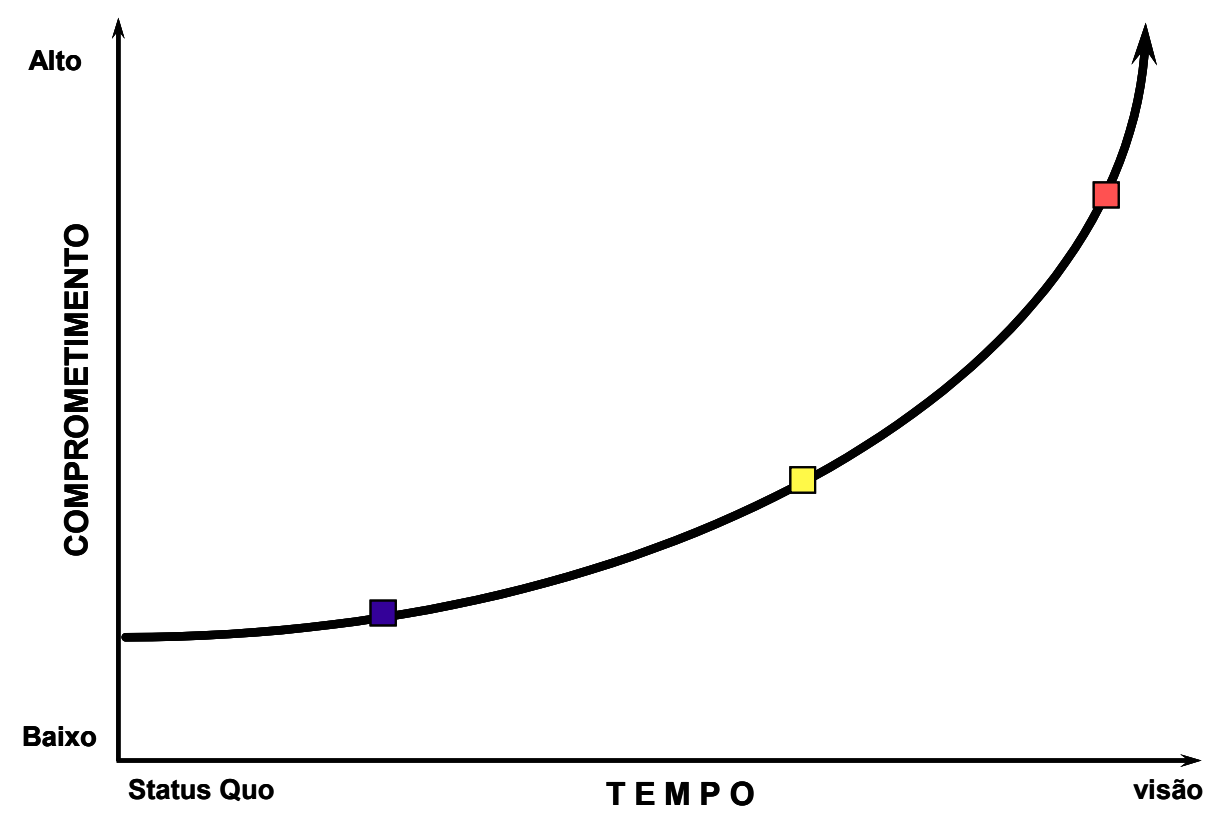

\subsubsection{Veículos de Comunicação}

- Informe Global One:

O Informe Global One é um jornal que passou a ser circulado internamente na companhia desde a fase de preparação, no qual os principais assuntos são disponibilizados para a organização como um todo (incluido a equipe de vendas, escritório de São Paulo, funicionários da fabrica no Rio e em Fortaleza, além dos funcionários do escritório no Rio)

- Minuto Global One:

O Minuto Global One é um informativo online que é periodicamente enviado por email para todos os funcionários da subsidiária brasileira com 0 objetivo de cada vez mais conscientizar os mesmos da importância do projeto e começar a prepará-los para as fases nas quais terão mais participação, como os treinamentos e principalmente para o Go-Live.

\subsection{Treinamento}

$70 \%$ das 1.000 maiores companhias do mundo identificam a falta de empregados treinados como a principal barreira ao seu crescimento contínuo. Um treinamento eficaz foi identificado como um dos fatores chaves de sucesso nas empresas que implementaram o SAP. 
Durante a implementação do Global One, existe uma fase específica para treinamento tanto dos super users quanto dos usuários finais, tal fase é vista como uma das mais importantes para o sucesso não só da implementação quanto principalmente para o sucesso da fase pós Go-Live.

A Figura abaixo ilustra as etapas de treinamento.

Figura 13

\section{As Etapas de Treinamento}

\begin{tabular}{|c|c|c|c|}
\hline $\begin{array}{c}\text { Etapa } 1 \\
\text { Blue Print }\end{array}$ & $\begin{array}{c}\text { Etapa } 2 \\
\text { Transferência de } \\
\text { Conhecimento }\end{array}$ & $\begin{array}{c}\text { Etapa } 3 \\
\text { Treinamento de } \\
\text { Instrutores }\end{array}$ & $\begin{array}{l}\text { Etapa } 4 \\
\text { Treinamento de } \\
\text { usuários finais }\end{array}$ \\
\hline $\begin{array}{c}\text { A Equipe Regional } \\
\text { do GO treina } \\
\text { Consultores e Super } \\
\text { Users }\end{array}$ & $\begin{array}{c}\text { Consultores treinam } \\
\text { Super Users }\end{array}$ & $\begin{array}{c}\text { A Equipe de } \\
\text { Treinamento treina } \\
\text { os Super Users }\end{array}$ & $\begin{array}{c}\text { Super Users treinam } \\
\text { usud́rios finais }\end{array}$ \\
\hline 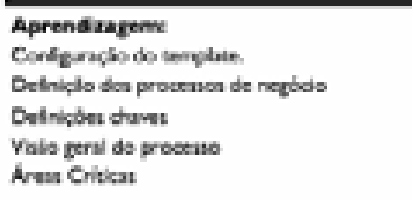 & 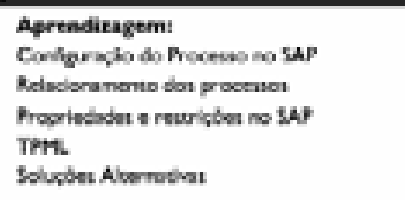 & 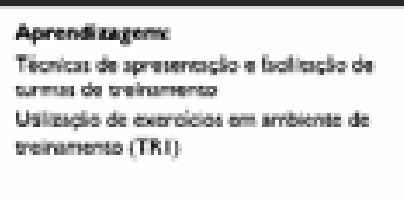 & 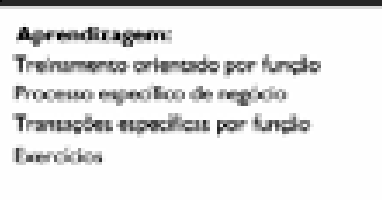 \\
\hline
\end{tabular}

Paralelamente a essas etapas, todo o material de treinamento é preparado conforme a figura abaixo: 
Figura 14

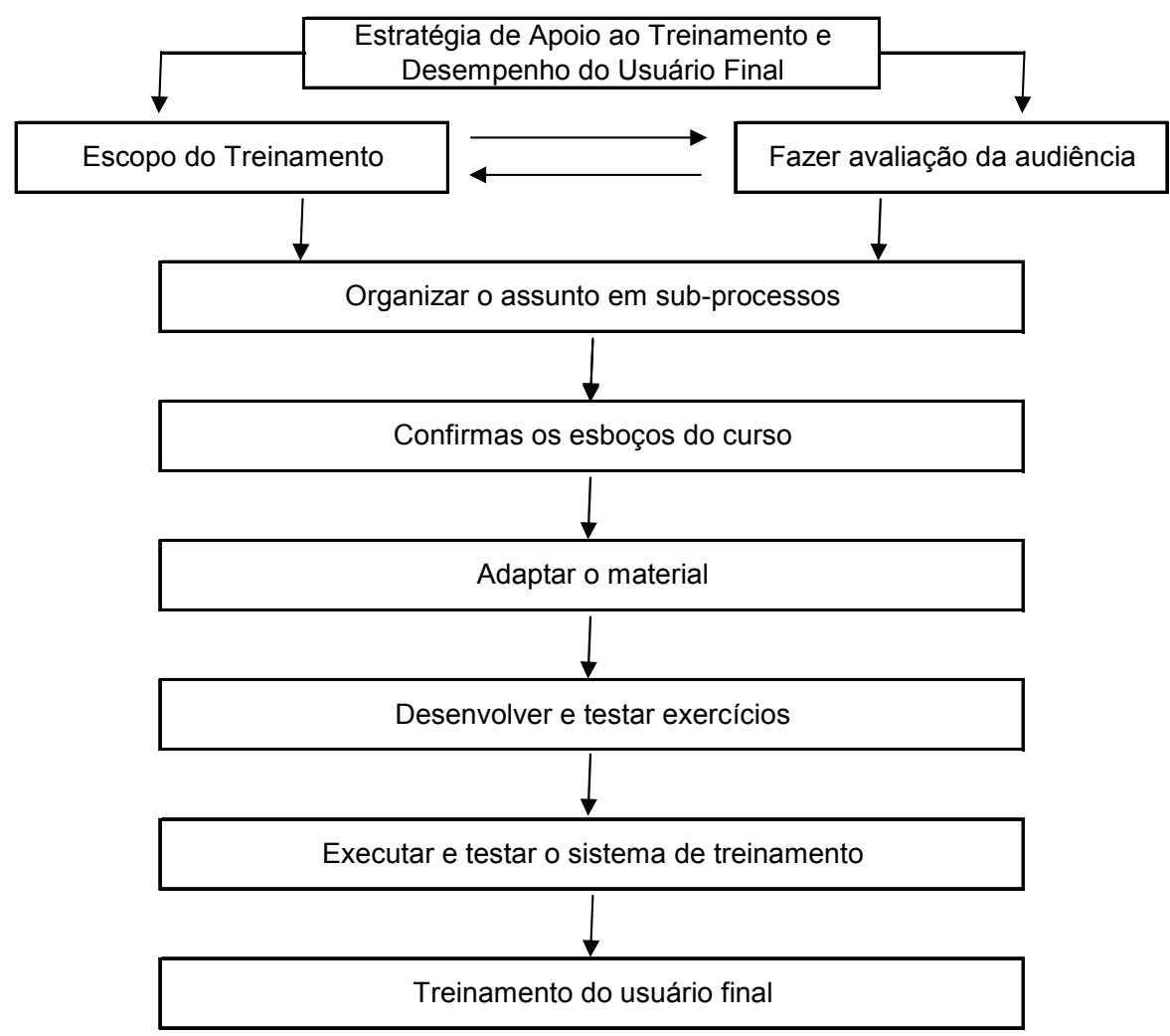

\subsection{Mudança - Plano de OCM}

O Global One tem tudo a ver com mudança. Segundo o presidente da subsidiária brasileira: "As mudanças podem ser, excitantes, desafiantes, e difíceis de conduzir, mas a única coisa sobre mudanças que pode ser controlada é a atitude."

De acordo com as figuras a seguir e em linha com a frase acimea mencionada, as pessoas são o que o projeto tem de mais importante e valioso. "Se quiser um ano de prosperidade, cultive cereais. Se quiser dez anos de prosperidade cultive árvores. Se quiser cem anos de prosperidade, cultive pessoas."

Em pesquisa realizada pela equipe da Deloitte Consulting and Benchmarking Partners, em 62 empresas que passaram por projetos de implementação de sistemas de ERP, as principais atividades estão relacionadas às pessoas $(62 \%)$, enquanto $16 \%$ está relacionado a processos, $9 \%$ a tecnologia, $3 \%$ a ativos de crescimento e $10 \%$ a outros. 
Figura 15

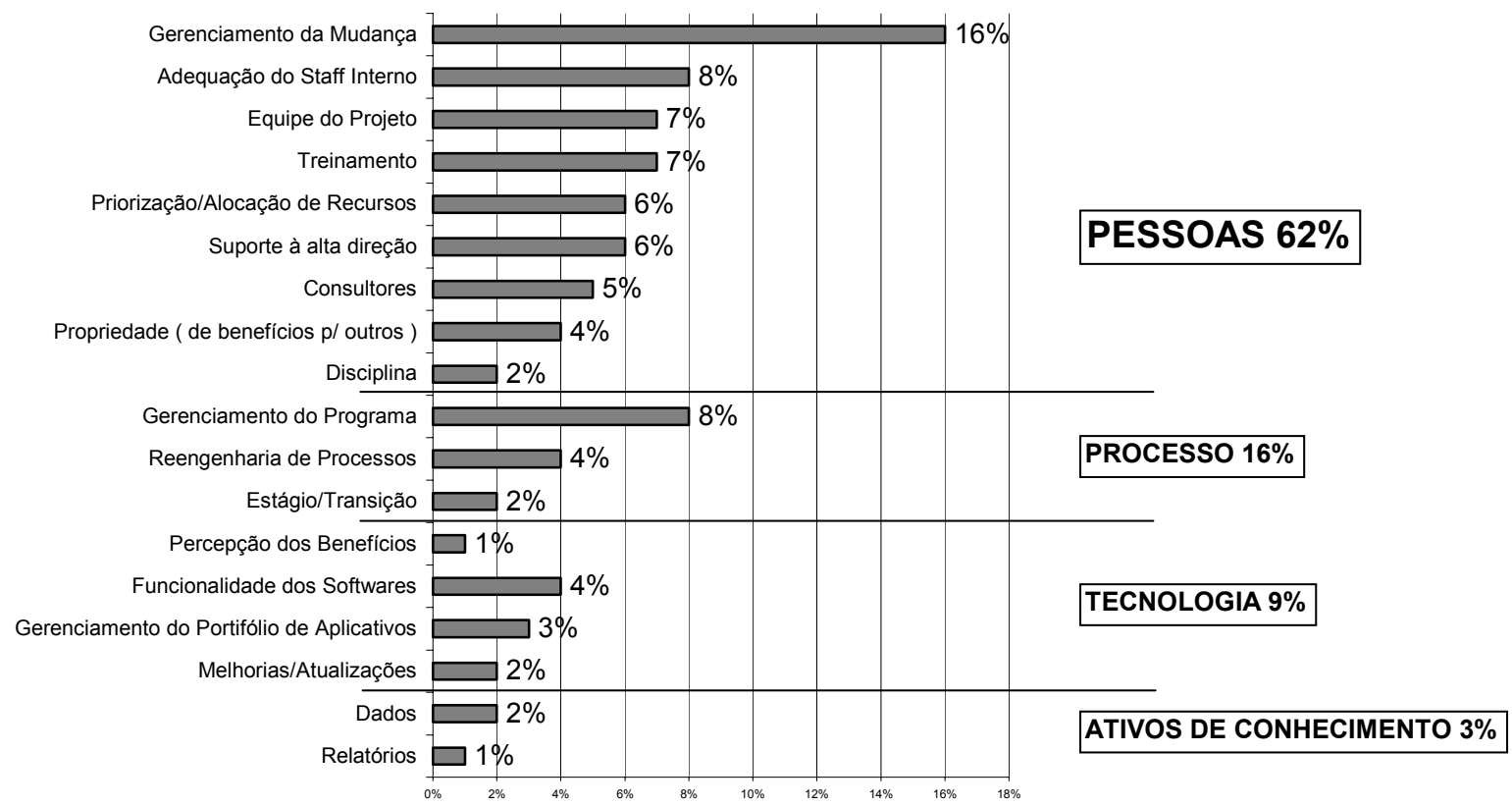

A figura abaixo, além da importância das pessoas, enfatiza que apesar das pessoas estarem preparadas, ainda assim irão passar por altos e baixos durante as etapas do projeto.

Figura 16

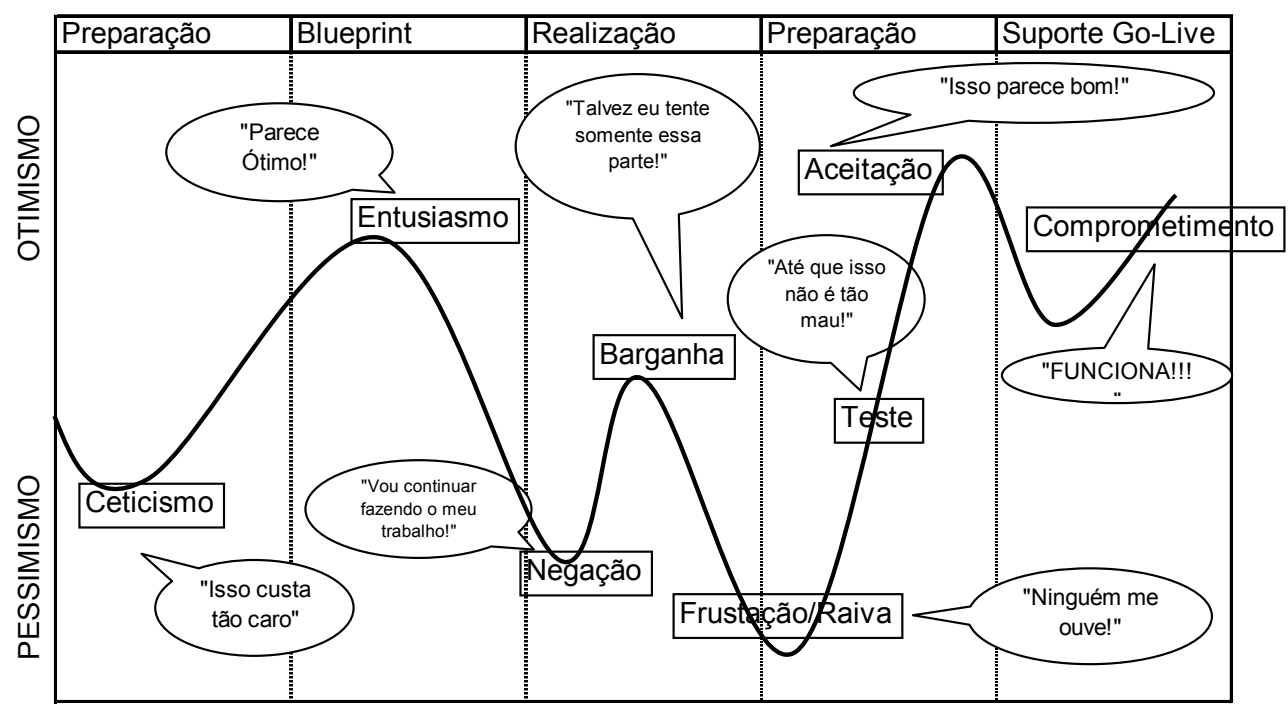




\subsubsection{Principais Atividades}

Figura 17

Plano Global One OCM - ONDA 3

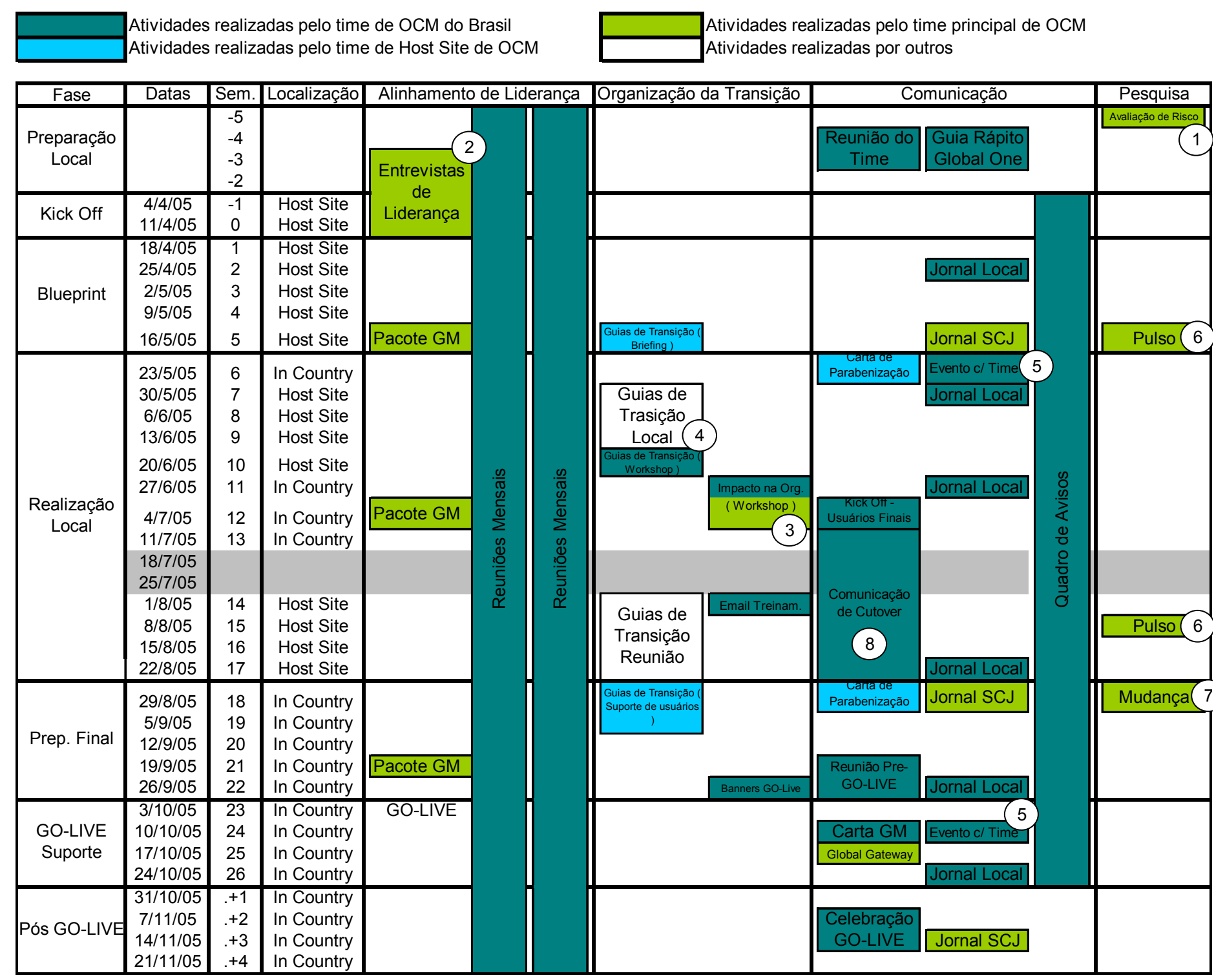

As principais atividades realizadas pelo time de Organization Change Menagment são:

1 - Pesquisa de Avaliações de Risco da Mudança e disponibilidade para a Mudança.

Pesquisa online com doze perguntas classificadas em cinco categorias, conduzida quatro vezes para cobrir um amplo público a cada vez.

O público participante foi o comitê de gerenciamento, o time de gerenciamento, os membros do host site e os super users. 
Objetivos:

- Avaliar o entendimento e comprometimento para o projeto Global One através da avaliação dos pensamentos, percepções e preocupações individuais.

- Desenvolver e refinar o plano de comunicação para conseguir endereçar as áreas de risco.

- Continuamente envolver os principais participantes no negócio.

\section{Resultados esperados:}

- Gerar um relatório de risco da mudança.

- Acompanhar as ações a serem determinadas.

Figura 18

\begin{tabular}{|c|c|c|}
\hline Clareza de Visão & Fábrica do Rio & $\begin{array}{l}\text { Escritório de } \\
\text { Vendas em SP }\end{array}$ \\
\hline 1. Compreendo os objetivos do Global One & $100 \%$ & $100 \%$ \\
\hline $\begin{array}{l}\text { 2. Compreendo e concordo que o Global One } \\
\text { é necessário }\end{array}$ & $100 \%$ & $100 \%$ \\
\hline \multicolumn{3}{|l|}{ Benefícios para o Negócio } \\
\hline $\begin{array}{l}\text { 3. Acredito que padronizar os procedimentos } \\
\text { do negócio central vai tornar nossa } \\
\text { organização mais eficiente e competitiva }\end{array}$ & $95 \%$ & $100 \%$ \\
\hline $\begin{array}{l}\text { 4. Os benefícios quantificados do Global One } \\
\text { e quando esses benefícios vão acontecer } \\
\text { estão claros }\end{array}$ & $85 \%$ & $83 \%$ \\
\hline $\begin{array}{l}\text { 5. As mudanças técnicas e comportamentais } \\
\text { exigidas para que os benefícios do Global } \\
\text { One aconteçam estão claras }\end{array}$ & $95 \%$ & $93 \%$ \\
\hline \multicolumn{3}{|l|}{ Liderança do Projeto } \\
\hline $\begin{array}{l}\text { 6. Está claro quem é responsável por } \\
\text { conseguir resultados e fazer do Global One } \\
\text { um sucesso em meu país }\end{array}$ & $100 \%$ & $100 \%$ \\
\hline $\begin{array}{l}\text { 7. As pessoas responsáveis por fazer do } \\
\text { Global One um sucesso estão cientes de } \\
\text { seus papéis, estão prontas e capacitadas } \\
\text { para participar }\end{array}$ & $97 \%$ & $100 \%$ \\
\hline \multicolumn{3}{|l|}{ Comprometimento } \\
\hline $\begin{array}{l}\text { 8. Considero a mim e meus subordinados } \\
\text { responsáveis por dar suporte às mudanças } \\
\text { exigidas pelo Global One }\end{array}$ & $98 \%$ & $100 \%$ \\
\hline $\begin{array}{l}\text { 9. Acredito que a diretoria em meu país está } \\
\text { comprometida com a implementação bem } \\
\text { sucedida do Global One }\end{array}$ & $100 \%$ & $100 \%$ \\
\hline $\begin{array}{l}\text { 10. Compreendo claramente qual é o meu } \\
\text { papel no Global One }\end{array}$ & $97 \%$ & $100 \%$ \\
\hline \multicolumn{3}{|l|}{ Recursos \& Iniciativas Competitivas } \\
\hline $\begin{array}{l}\text { 11. Foram alocados tempo e recursos para } \\
\text { garantir o sucesso do Global One }\end{array}$ & $94 \%$ & $100 \%$ \\
\hline $\begin{array}{l}\text { 12. Compreendo o plano para manter nosso } \\
\text { negócio enquanto damos suporte à } \\
\text { implementação do Global One }\end{array}$ & $95 \%$ & $100 \%$ \\
\hline
\end{tabular}


2 - Entrevista com os principais líderes da organização.

Entrevistas individuais com duração de uma hora a uma hora e meia conduzida pelo membros o time principal de OCM cara a cara com os lideres dos principais departamentos impactados dos quais o suporte é crítico para o sucesso do projeto.

Objetivos:

- Prover oportunidade para os principais lideres levantarem e discutirem suas dúvidas e idéias.

- Para claramente definir a quantidade e o tipo de suporte requerido pelo time do projeto.

- Prover um veículo que permita aos lideres influírem em como o projeto será implementado.

Resultados esperados:

- Preparar planos para assistir os lideres a demonstrar suporte.

- Documentar os problemas em prioridades, iniciativas conflitantes, recursos ou outros altos riscos e mostrá-los como requerimentos.

- Construir conhecimento e entendimento aos times sobre os problemas, idéias e preocupações do pessoal de negócio.

3 - Workshops de Impacto Organizacional

Uma série de pequenos grupos divididos por tópicos referentes às áreas de processo. Tais grupos serão formados pelos gerentes e diretores do negócio e os membros do time do projeto e do time de OCM agirão como facilitadores.

Objetivos:

- Avaliar os impactos organizacionais no negócio com o resultado da implementação do projeto.

- Determinar ações que deverão ser tomadas para endereçar os impactos assim como suportar a performance do processo de negócio, sua estrutura, relatórios depois da implementação.

Resultados esperados:

- Definir os planos de transição organizacional

- Integração / Treinamento

- Comunicação / Envolvimento 
4 - Guias de transição

Estão disponíveis quatorze guias de transição para os negócios mais impactados. Os super users tem o papel de repassar esses guias para os usuários finais.

Objetivos:

- Prover uma ferramenta de comunicação que os gerentes poderão usar para abrir a conversa com seus funcionários sobre as mudanças que irão impactar o seu dia a dia.

- Diminuir a ansiedade e endereçar as perguntas sobre os impactos aos funcionários o quanto antes.

- Prover uma preliminar sobre as mudanças específicas que virão com o projeto.

Resultados esperados:

- Os funcionários poderão ficar verdadeiramente focados em adquirir habilidades técnicas durante os treinamentos aos usuários finais em vez de ficarem ansiosos sobre o que as mudanças significarão para cada um deles.

- Os gerentes terão domínio do processo de mudança.

5 - Eventos com os times

Uma oportunidade para a socialização dos membros do time do projeto.

Objetivos:

- Comemorar a realização do marco.

- Facilitar a socialização do time e provocar um ambiente relaxante.

- Reduzir o stress gerado pelo projeto.

6 - Pesquisa de oscilação / vibração.

Pequena pesquisa online com cinco minutos de duração, realizada com os membros do host site e com os super users.

Objetivos:

- Avaliar a efetividade das dinâmicas, operações e comunicações.

- Identificar possíveis áreas que necessitem de melhorias. 
Resultados esperados:

- Planos de ação para criar melhores prática e endereçar possíveis problemas.

7 - Pesquisa de prontidão para o GO-LIVE

Pesquisa online realizada com os usuários finais do SAP.

Objetivos:

- Avaliar se os usuários finais e os líderes organizacionais estão preparados para o Go-Live.

- Acompanhamento do treinamento

- Entendimento de um modelo futuro de suporte

8 - Comunicação do momento da mudança

Comunicado realizado através de cartas e emails aos vendedores, clientes, bancos e internos.

Objetivos:

- Assegurar que todos estão informados sobre as mudanças que virão como resultado da implementação.

- Notificar os internos sobre os comunicados aos externos e mostrar suas responsabilidades como parte dessa comunicação.

9 - Comunicação local

Canais de comunicação desenvolvidos como o quadro de avisos, publicações, reuniões etc.

Objetivos:

- Prover a quantidade correta de informação para o público alvo no momento certo via os corretos canais para encontrar as necessidades do time de negócio. 


\section{Conclusão}

Além da opinião como autora dessa monografia, estarei acrescentando opiniões para concluir esse trabalho como membro do time que está trabalhando na implementação desse projeto no Brasil pois desde meados de Abril faço parte desse time como Super User de um dos subprocessos da companhia.

A questão chave que direciona esse trabalho se refere a maneira como a empresa irá gerenciar a mudança necessária para implementação desse novo modelo de gestão. Tal assunto foi explorado durante a confecção da análise crítica a qual deixa claro que tudo está sendo feito seguindo as regras e procedimentos globais. Como implementações já foram bem sucedidas em outras subsidiárias da empresa, seguindo o mesmo modelo acredita-se que o mesmo acontecerá no Brasil. Sem dúvida, existem inúmeras diferenças entre tais países e é em função disso que parte do chamado Global Template é constituida de adaptações locais. Portanto, as particularidades, principalmente em relação às questões fiscais no país estão sendo exaustivamente expostas para que o time Global se convença de que as mesmas poderiam se tornar impeditivas à conclusão do projeto. Uma das maiores dificuldades encontradas nessa etapa é justamente conseguir que tudo que imaginamos ser uma diferença entre o modelo global e as necessidades locais sejam realmente classificados como gaps, pois somente assim serão solucionados.

Ao mesmo tempo que o time global quer o mínimo possível alterar o global template, os brasileiros tentam se assegurar de que tudo foi levantado e questionado pois a partir de uma determinada data não será possível abrir mais gaps uma vez que o projeto deve prosseguir e não se aceita em hipótese alguma que a data de trasição não seja cumprida.

Tendo isso em vista classifico esse como o principal risco do projeto uma vez que podemos constatar tarde demais que certas coisas não foram corretamente mapeadas com a antecedência requerida. A princípio não temos certeza de qual será a flexibilidade em casos como esse. Outro ponto que enfatiza essa questão, é o fato de termos uma equipe enxuta e tempo escasso o que faz com que as decisões devam ser tomadas de forma rápida o que pode acabar gerando muito retrabalho no futuro ou até processos manuais de reconciliação.

Por outro lado, a diretoria da empresa está totalmente alinhada com todos os passos que estão sendo dados ao longo do projeto o que aumenta a 
importância que deva ser dada e os cuidados a serem tomados quanto ao planejamento dessa mudança.

O planejamento da mudança nesse projeto consiste em garantir que todas as etapas pré elaboradas pelo modelo global sejam cumpridas, nota-se que todos os fatores críticos de sucesso mencionados pelos autores citados nesse trabalho estão corretamente cobertos através de todo esse planejamento. Porém sabe-se também que nem sempre o que é planejado é implementado, mas essa é uma questão que também está muito bem coberta pois para cada tarefa há um controle de status o que garante que nenhuma tarefa seja esquecida ou mesmo não concluída.

Outro ponto que aumenta as chances de sucesso é o fato desse projeto realmente estar sendo encarado como a prioridade número um da companhia nesse ano e para isso foram selecionados os melhores funcionários em suas funções originais, já que não adianta um planejamento muito bem elaborado como esse sem que haja quem o concretize. Para isso está sendo prometido um sistema de reconhecimento e recompensa para todos os participantes do projeto.

Projetos como este costumam ser demorados e caros porém o que se vê na SCJ Brasil é que tudo estará pronto e funcionando em apenas vinte e seis semanas. Nada disso seria possível se não estivéssemos utilizando um modelo de planejamento muito bem estruturado e devidamente testado, se não contássemos com pessoas que foram treinadas para evitar que sejam resistentes às mudanças e que se tornem cada vez mais flexíveis e proativas e sem que todos os objetivos fossem corretamente alinhados.

Conforme mencionado no referencial teórico, a estratégia de implementação via conversão direta é a mais arriscada e é a que será utilizada pela Ceras Johnson. Contudo existe uma grande confiança de que o planejamento cobre todos os fatores que geram os riscos iminentes, ao mesmo tempo, no pior caso, se a empresa estiver impossibilitada de dar proceguimento às suas atividades corriqueiras ainda há o chamado Risk Mitigation.

O Risk Mitigation não é um plano de contingência pois não surge a partir do momento em que algo deva ser corrigido mas sim como o próprio nome diz, sua função é de atenuar o risco. Caso tudo dê errado, a empresa estaria protegida por um mês pois todos os seus clientes serão devidamente estocados para terem a capacidade de garantir o atendimento dos consumidores durante um mês sem fora de estoque, ou seja a empresa não perde vendas, não perde 
participação de mercado, não perde distribuição, pelo contrário, pode até tirar proveito dessa situação, uma vez que estará antecipando suas vendas.

Após o go-live, sabemos que grande parte do suporte ao sistema será dado pelas equipes globais e regionais porém não sabemos na prática se esse suporte atenderá às necessidas da localidade uma vez que outros muitos países também demandarão desse suporte e teremos que dividir o tempo dessas pessoas com outros países em muitas vezes mais prioritários devido à representatividade dos mesmos.

Apesar de toda a comunicação, é difícil evitar a especulação que é gerada e principalmente os rumores acerca de possíveis demissões após a implementação. Sabe-se que algumas áreas terão suas atividades reduzidas e outras aumentarão o trabalho no dia a dia, portanto mesmo que sem fundamentos concretos, paira uma sensação de insegurança entre os funcionários que ficaram em seus postos de trabalho, entre os substitutos que foram alocados nas posições dos funcionários que se movimentaram para 0 Global One assim como entre os temporários que foram contratados para suportar demandas esporádicas.

Outra expectativa, porém essa mais a longo prazo, é quanto ao retorno financeiro proveniente dessa mudança. Espera-se que em quatro anos a empresa recupere todo o investimeno e passe a ser lucrativa.

Contudo, no curtíssimo prazo, o que os funcionários realmente esperam é que os problemas aconteçam. Antes agora do que depois da transição. 
6. Glossário

SCJ - Samuel Curtis Johnson, abreviatura do nome da Johnson.

SAP - Systems, Applications and Products. É a companhia de software que vende um sistema de gestão de negócios que leva seu nome.

Global One - Nome do projeto para implementação do SAP nas subsidiárias da SCJ.

R/3 - Runtime System Three. É o número da versão do software SAP adquirido pela SCJ.

BW - Business Warehouse. É o módulo do SAP utilizado para armazenagem dos dados.

PMO - Project managment owner. 


\section{Bibliografia}

\section{Livros:}

CHIAVENATO, Idalberto. Introdução à Teoria Geral da Administração. 5.ed. Rio de Janeiro: Campus, 1999.

PRUE, D. M. \& Frederikson, L. W. ( 1982 ). Overcoming resistance to change. In L. W. Frederikson ( Ed. ) Handbook of organization behavior. New York: Wiley.

WEIK, K. E. ( 2000 ). Emergent change as a universal in organizations. In M. Beer \& N. Nohria ( Eds. ), Braking the code of change. Boston, MA: Harvard Business School Press.

NUTT, P. \& BACKOFF, R. ( 2001 ). A trasformação das organizações contemporânias. In M.P. Cunha, J. M. Fonseca \& F. Gonçalves ( Eds. ). Empresas caos e complexidade: gerindo a beira de um ataque de nervos. Lisboa: RH-Editora.

PFEFFER, J. ( 1992 ) Managing with power: Politics and Influence in Organization. Boston, MA: Harvard Business School Press.

STANISLAO, J. \& STANISLAO, B. C. ( 1983 ). Dealing with resistance to change. Business Horizons.

GONÇALVEZ, Renata C. O Impacto da Cultura na Performance Organizacional: Um Estudo de Caso. Rio de Janeiro: PUC-RIO, 2003. Dissertação de Mestrado.

VERGARA, Sylvia Constant. Projetos e Relatórios de Pesquisa em Administração. São Paulo: Atlas,1997.

MOURA, Maria Lucia Seidl \& FERREIRA, Maria Cristina \& PAINE, Patrícia Ann. Manual de Elaboração de Projetos de Pesquuisa. Rio de Janeiro: UERJ, 1998. 
CERVO, Amado L. \& BERVIAN, Pedro A. Metodologia Científica. São Paulo: Afiliada, 2003.

THOMPSON, Augusto. Manual de Orientação para Preparo de Monografia. São Paulo: Forense, 2000.

ECO, Humberto. Como se faz uma Tese. São Paulo: Perspectiva, 1983.

BRESLIN, Jud. Selecting and installing software packages. IWest port, Connecticut, 1986.

PISZCZALSKI, Martin. Lessons learned from Europe's SAP users. 1997.

LOZINSKY, Sergio. Software: tecnologia do negócio: em busca de benefícios e de sucesso na implementação de pacotes de software integrados. Rio de Janeiro - Imago, 1996.

RODOSEVICH, Lynda. Quantum's leap. CIO Magazine, 1997.

KRUGLIANSKAS, Isaac. Engenharia simultânia: organização e implementação em empresas brasileiras. Revista de administração, SP, 1993.

SLEVIN, Denis \& PINTO, Jeffrey K. P. The project implementation profile: new tool for project managers. 1986.

GROVER, Varum. The implementation of business process reengineering, 1995.

LARSEN, Melissa A. \& MYERS, Michael D. BPR success failure? A business process reengineering project in the financial services industry. 1997.

HAMMER, Maichael \& CHAMPY, I. Reengineering the corporation: a manifesto for business revolution. London, 1993. 
BANCKOFT, Nancy $\mathrm{H}$. Implementing SAP R/3: how to introduce a large systen into a large organization. 1998.

\section{Artigos e Apostilas:}

TOMEI, Patrícia Amélia. A Gerência da Cultura como Ferramenta de Competitividade. Rio de Janeiro, 2002.

SOUZA, Vanda. Como fazer mudanças: 10 fases para implementação de Mudança Organizacional.

Internet:

http://www.iteci.com.br/adm upload/imagens/gestaohoje01.htm

http://www.dinsmore.com.br/ngm/artigosvanda.htm

http://www.apics.org/aboutapics/abtztop.htm 